\title{
DEBERES JURÍDICOS Y CONVICCIONES MORALES EN EL ORDENAMIENTO ESPAÑOL
}

MARÍA JOSÉ CIÁURRIZ 
SUMARIO

\begin{abstract}
1. LA OPOSICIÓN ENTRE DEBER JURÍDICO Y CONVICCIÓN MORAL COMO ORIGEN DE LA OBJECIÓN DE CONCIENCIA. 1.1. Deberes jurídicos y convicciones morales. 1.2. El concepto de objeción de conciencia. 2. LA OBJECIÓN DE CONCIENCIA ANTE EL DERECHO. 2.1. El reconocimiento normativo de la objeción. 2.2. La tutela del derecho a la objeción de conciencia. 3. LAS OBJECIONES DE CONCIENCIA ANTE EL DERECHO ESPAÑOL. 3.1. La tutela de la objeción en el actual sistema constitucional. 3.2. La única objeción de conciencia expresamente mencionada en la Constitución de 1978: el servicio militar. 3.3. Las objeciones de conciencia en el ámbito biológico. 3.3.1. El aborto. 3.3.2. Los tratamientos médicos. 3.3.3. El consentimiento informado. 3.3.4. Las instrucciones previas o testamentos vitales. 3.3.5. La reproducción asistida. 3.3.6. La eutanasia. 3.3.7. La objeción de conciencia farmacéutica. 3.4. Las objeciones de conciencia en el ámbito público. 3.4.1. La objeción fiscal. 3.4.2. Objeción de conciencia y relaciones laborales. 3.4.3. El juramento. 3.4.4. La objeción a formar parte de un jurado. 3.4.5. Los matrimonios entre personas del mismo sexo. 3.4.6. La simbología religiosa. 3.5. Especial referencia a la objeción de conciencia en el sector de la educación.
\end{abstract}




\title{
DEBERES JURÍDICOS Y CONVICCIONES MORALES EN EL ORDENAMIENTO ESPAÑOL
}

\author{
MARÍA JOSÉ CIÁURRIZ \\ Universidad Nacional de Educación a Distancia
}

\section{LA OPOSICIÓN ENTRE DEBER JURÍDICO Y CONVICCIÓN MORAL COMO ORIGEN DE LA OBJECIÓN DE CONCIENCIA}

\subsection{Deberes jurídicos y convicciones morales}

Se ha definido a la objeción de conciencia como «la oposición al cumplimiento de aquellos deberes jurídicos incompatibles con las más profundas convicciones morales de una persona», afirmando al par que la misma constituye un «derecho fundamental en el ordenamiento jurídico español» ${ }^{1}$. Y aunque las presentes páginas hacen especial referencia a este ordenamiento, su tema no es ciertamente exclusivo ni de España ni de ningún otro país concreto, sino que posee dimensiones universales, y puede ser analizado en dos planos diferentes: el de la coherencia de la conducta humana con las convicciones éticas propias de cada persona, y el de la toma en consideración por parte de los varios Estados del deber moral que para el individuo se deriva de la incompatibilidad entre su ideología y el ordenamiento.

Cabe en efecto afirmar que un Estado democrático no puede ignorar el derecho a la objeción de conciencia frente a la norma que el individuo considera injusta; pero no es menos cierto que una regulación de la objeción que tratase de

${ }^{1}$ G. Escobar Roca, La objeción de conciencia en la Constitución española, Centro de Estudios Constitucionales, Madrid 1993, p. 33. 
tomar en consideración cada una de sus múltiples variantes sumergiría al Estado en una absoluta situación de caos. Incluso es así cuando se pone en directa relación la objeción con la libertad religiosa - lo que como veremos no es una constante necesaria-, ya que incluso esta libertad «no es un derecho absoluto ni ilimitado, no todas las reivindicaciones de raíz religiosa son atendibles en el ordenamiento democrático ${ }^{2}$. Estamos, en efecto, ante la confrontación entre la libertad y el cumplimiento de la norma jurídica, una situación en la cual, «en la hipótesis de que el Estado se decidiera sin restricciones por el primer interés protegido [la libertad de la conciencia] peligraría su propia subsistencia, al permitir que la conciencia de cada individuo, regla y norma de sí misma, prevaleciera como un valor absoluto por encima de las reglas comunes que hacen posible las relaciones interpersonales en la elemental clave de paz social y seguridad jurídica que el derecho siempre busca. Pero, si se decidiera absolutamente por el segundo - el cumplimiento a ultranza de la norma general, aun adoptada por legítimos mecanismos democráticos- convertiría en ficción uno de los pilares fundamentales de su propia naturaleza» ${ }^{3}$.

El orden jurídico no puede, en efecto, verse alterado hasta su límite por una inagotable serie de posibles convicciones éticas de cada ciudadano en particular; pero tampoco puede verse sometida la conciencia a un absoluto e inevitable deber de obediencia a las leyes que conduciría, en última hipótesis, a la transformación del Estado en dictadura y del Derecho en tiranía. La historia es rica en ejemplos que avalan esta afirmación, y no es casual que la mayor parte de ellos procedan de un contraste entre las convicciones religiosas y los deberes civiles; no en vano, y durante muchos siglos, se han identificado las convicciones morales con las propias de cada religión determinada. Justamente el conflicto procede del intento - presente, hasta hoy, en tantos momentos de la historia - por parte del Estado de sustituir la moral religiosa por una ética estatal, autoconsiderándose como la fuente de la que nacen los principios éticos ${ }^{4}$. No deja de ser significativo que, cuando surgieron los enfrentamientos entre cristianismo e Imperio romano, los criterios morales los definía el poder político, y los cristianos, en tanto que opuestos a algunos de los mismos, son acusados de «pertenencia a una secta a la que se atribuyen costumbres contrarias a la moral»s.

${ }^{2}$ A. Barrero Ortega, «Multiculturalismo y libertad religiosa», en Anuario de Derecho Eclesiástico del Estado, XXVII, 2011, p. 37.

${ }^{3}$ R. Navarro-Valls, J. Martínez-Torrón, Conflictos entre conciencia y ley, Iustel, Madrid 2011, pp. $35-36$

${ }^{4}$ Sobre el actual fenómeno de la secularización del Estado, en cuanto que tiende a convertirse en sustituto de toda religión, vid. D. Negro Pavón, Cristianismo y religión secular, Ateneo Jovellanos de Gijón, 2009.

${ }^{5}$ J. Daniélou, «Desde los orígenes al Concilio de Nicea», en L. J. Rogier, R. Aubert, M.D. Knowles, Nueva Historia de la Iglesia, tomo I, Ediciones Cristiandad, Madrid 1964, p. 126. 
La idea, pues, de una disyuntiva entre deberes jurídicos y convicciones morales, ha llegado hasta nosotros a través de una larga experiencia plurisecular, en la que se han ido desarrollando las diferentes corrientes doctrinales, polarizadas en torno a la dificultad de mantener, en los casos conflictivos, la obediencia a un tiempo a los deberes de conciencia y a los deberes sociales. De aquí nace una tensión, con evidentes raíces políticas ${ }^{6}$, que conduce a las corrientes más extremas al temor de que tras la aceptación de la objeción se oculte la amenaza de invencibles, o al menos gravemente complicadas, alteraciones del orden jurídico. Y es precisamente esto lo que no ha de producirse, cuado se logra encontrar la vía de convivencia entre el derecho del ciudadano a ser fiel a su convicciones y el del Estado a regular la convivencia social en un marco de justicia, pluralismo, igualdad y libertad, tal como proclama la Constitución española en su artículo $1.1^{7}$ al enumerar los valores superiores del ordenamiento jurídico, que deben ser entendidos «como la manifestación de los máximos objetivos que se impone a sí mismo el régimen constitucional» ${ }^{8}$.

\subsection{El concepto de objeción de conciencia}

La Declaración Universal de Derechos Humanos de las Naciones Unidas, de 1948, establece en su artículo 18 que «toda persona tiene derecho a la libertad de pensamiento, de conciencia y de religión» ${ }^{9}$; si del ámbito general pasamos al particular de España encontramos, de un lado, que dicho precepto constituye un criterio de interpretación de «las normas relativas a los derechos fundamentales y a las libertades que la Constitución reconoce» ${ }^{10} \mathrm{y}$, de otro lado, que el art. 16.1 del

${ }^{6}$ La praxis jurídica de los diversos Estados ha tratado de encontrar fórmulas para reducir esta tensión, tal como se ido poniendo de manifiesto a partir del conocido caso del Rey Balduino de Bélgica en su oposición a la ley del aborto (vid. al propósito J. M. Sánchez García, «Monarquía parlamentaria y objeción de conciencia. El caso del Rey de los Belgas», en Anuario de Derecho Eclesiástico del Estado, IX, 1993, quien hace expresa referencia - p. 294- a los problemas que necesariamente surgen «si la objeción de conciencia se alza contra la orientación jurídica predominante»).

7 «España se constituye en un Estado social y democrático de Derecho, que propugna como valores superiores de su ordenamiento jurídico la libertad, la justicia, la igualdad y el pluralismo político».

${ }^{8}$ Vid. Y. Gómez Sánchez, Introducción al régimen constitucional español, $3^{\mathrm{a}}$ ed., Editorial Sanz y Torres, Madrid 2003, pp. 325-326.

9 Vid. en J. Fornés. M. Blanco, B. Castillo, F. Pérez-Madrid, Legislación eclesiástica, ThomsonAranzadi, Cizur-Menor 2006, p. 32.

${ }^{10}$ Constitución española (en adelante CE), art. 10.2: «Las normas relativas a los derechos fundamentales y a las libertades que la Constitución reconoce, se interpretarán de conformidad con la Declaración Universal de Derechos Humanos y los tratados y acuerdos internacionales sobre las mismas materias ratificados por España». 
mismo texto constitucional establece una garantía que protege en España «la libertad ideológica, religiosa y de culto» ${ }^{11}$.

Los términos utilizados por dicho art. 16.1 han dado lugar a diferentes opiniones por parte de la doctrina sobre la distinción entre la libertad ideológica y la religiosa, o la consideración de ésta como un sector específico de aquélla ${ }^{12}$. Se han manifestado diversas en especial dos corrientes doctrinales, en cuanto que se considere o no a ambas libertades como dos derechos fundamentales distintos entre $\mathrm{si}^{133}$; puede decirse que, en lo que hace a la mención de ambas libertades en el texto constitucional, «el contenido de la libertad ideológica es análogo al de la libertad religiosa en lo que ambas tienen de inmunidad o protección del agere licere: profesar una creencia, laica o religiosa» ${ }^{14}$. Hoy está aceptado por la doctrina que en el moderno pluralismo se entremezclan estas ideologías, que provienen de diversas fuentes, lo que permite en efecto el uso de la palabra «profesar» —un término clásico de la adhesión a credos de fe- para referirse a cualquier tipo de creencias; un detalle tal vez nimio, pero revelador de que «il pluralismo religioso dell'Europa si trasforma in pluralismo etico e culturale» ${ }^{15}$. Y no es menos de señalar la distinción entre la libertad de conciencia y la objeción de conciencia, que se percibe en el hecho de que, reconocida la primera - como acabamos de indicar- en el art. $16 \mathrm{CE}$, la segunda «en cuanto que presupone la existencia de una norma imperativa que obliga a un comportamiento contra la conciencia, exige, en cada caso, la excepción al cumplimiento de la norma prescrita» ${ }^{16}$.

El texto de la Declaración Universal resulta en esto más categórico, puesto que distingue con claridad entre la libertad de religión, la de pensamiento y la de conciencia. Ésta última, en tanto que no identificada con la libertad religiosa, nos

${ }^{11}$ «Se garantiza la libertad ideológica, religiosa y de culto de los individuos y las comunidades sin más limitación, en sus manifestaciones, que la necesaria para el mantenimiento del orden público protegido por la ley».

${ }^{12}$ En los textos internacionales aparecen diversos enunciados de estas libertades, que pueden catalogarse según variados criterios, en torno a las ideas de creencia, pensamiento, conciencia, religión (vid. S. Quesada Polo, «El Convenio europeo de derechos humanos», en Y. Gómez Sánchez (coord.), Los derechos en Europa, UNED, Madrid 1999, p. 140).

${ }^{13}$ La doctrina ha aludido también a lo que se ha calificado como «la pretendida equiparación entre los sujetos titulares de las libertades ideológica y religiosa» (A. Barrero Ortega, La libertad religiosa en España, Centro de Estudios Políticos y Constitucionales, Madrid 2006, pp.105-112).

${ }^{14}$ L. Prieto Sanchis, «El derecho fundamental de libertad religiosa», en I. C. Ibán, L. Prieto, A. Motilla, Manual de Derecho Eclesiástico, Editorial Trotta, Madrid 2004, p. 59.

${ }^{15}$ S. Ferrari, «Diritto e religione nello Stato laico: islam e laicità, en G. E. Rusconi, Lo Stato secolarizzato nell'età post-secolare, Il Mulino, Bologna, p. 317.

${ }^{16}$ A. Castro Jover, «La libertad de conciencia y la objeción de conciencia individual en la Jurisprudencia constitucional española», en J. Martínez-Torrón (ed.), La libertad religiosa y de conciencia ante la justicia constitucional, Editorial Comares, Granada 1998, p. 133. 
muestra el dato de que las motivaciones de conciencia no resultan necesariamente inspiradas en razones de contenido religioso. Y, así, el ámbito de las objeciones de conciencia no debe confundirse con un espacio radicado en el campo de la religión. No lo excluye, pero no se limita a él.

Ha de partirse de la base de la distinción entre libertad de conciencia y objeción. La primera es un derecho fundamental de la persona humana; la segunda constituye «una situación de conflicto entre el derecho y su límite», que puede ser definida como «la libertad de conciencia en caso de conflicto» o, «más exactamente, como la situación en que se halla la libertad de conciencia cuando algunas de sus modalidades de ejercicio encuentran frente a sí razones opuestas derivadas de una norma imperativa o de la pretensión de un particular» ${ }^{17}$.

De la creciente incidencia en nuestros días de esta singular manifestación de la libertad humana da testimonio la doctrina cuando señala que «uno de los fenómenos más llamativos que conoce el derecho contemporáneo es el de la objeción de conciencia, o, si se quiere, el de los conflictos entre ley y conciencia», a partir del dato — al que hoy somos muy particularmente sensibles - de que «la cuestión de la contradicción posible entre normatividad legal y normatividad ética es inherente a la propia noción de orden jurídico y al ejercicio racional de la individualidad humana» ${ }^{18}$. De ahí que quepa decir que el Estado, o el poder político, al par que no le corresponde conceder al hombre aquellas libertades que son inherentes a la naturaleza humana, sí que en cambio ha de reconocerlas y garantizarlas; y la protección de la objeción de conciencia es sin duda una de las posibles garantías que el ordenamiento jurídico puede ofrecer a la correspondiente libertad. Y no es necesario, por supuesto, recurrir exclusivamente a las motivaciones religiosas de las opciones de conciencia, que sitúan a la objeción en relación directa con la libertad de elegir y practicar la religión que cada persona desee; la conciencia no se rige tan sólo por motivaciones de fe, ya que «el término “convicción” es amplio y no se restringe a una determinada fe, más bien se extiende a todas las convicciones relacionadas con la existencia y el destino del hombre» ${ }^{19}$; no menos cierto resulta que «a veces la ética laica no es capaz de resolver cuestiones críticas, por lo que cabe recurrir a motivaciones religiosas para articular una respuesta» ${ }^{20}$. Una afirmación que nos señala el difícil deslinde entre la conciencia conformada por las creencias religiosas o por otros tipos de convicciones, ambas dignas de respeto y latentes en toda esta problemática.

\footnotetext{
${ }^{17}$ L. Prieto Sanchis, ob. cit., p. 78.

${ }^{18}$ R. Navarro-Valls, J. Martínez-Torrón, ob. cit., p. 23.

${ }^{19}$ R. Arnold, «Evolución de los derechos en Europa», en Y. Gómez Sánchez (coord.), Los derechos en Europa, cit., p. 80.

${ }^{20}$ E. Guillén López, «Representación política y libertad religiosa», en El Cronista del Estado Social y Democrático de Derecho, 10, febrero 2010, Iustel, p. 46, que cita a K. Greenwalt, Religious convictions and political Choice, Oxford University Press, New York, Oxford 1988, p. 12.
} 
La cuestión está en determinar —al referirnos a la actitud que ha de tomar el Estado en orden a la garantía de la objeción en cuanto derecho fundamental-, si es «puede» el término adecuado al caso, o si en vez de «puede» habrá de decirse «debe». La respuesta no es fácil, y en ella radica uno de los problemas centrales con que la doctrina y los legisladores se encuentran hoy al afrontar esta temática. Dada la estrecha relación que existe entre objeción de conciencia y ética —ya hemos recogido más arriba una referencia a la «normatividad ética»—, es evidente que nos encontramos ante un conflicto acerca de los orígenes de los valores; si se considera que el Estado es el único definidor de éstos, no aceptándose que el ser humano posee un código de valores que el Estado no puede determinar ni reducir, entonces el poder se convierte en totalitario o tiránico, la conciencia queda sometida a su dictado, y se evapora la libertad. Si en cambio, como lo mejor de la doctrina defiende, existe una conciencia libre que el Estado no puede subyugar, el reconocimiento y la garantía jurídicos de la objeción de conciencia resultan ser un postulado ineludible de todo Estado que se defina como democrático o como «Estado de Derecho».

Es cierto que, en la realidad de los actuales ordenamientos jurídicos en todo el mundo, podremos a este respecto encontrar tres modelos: los Estados que rechazan toda objeción de conciencia ${ }^{21}$, los que no la incluyen de modo expreso en su legislación pero tampoco la prohíben, y los que le dan de algún modo cabida en su normativa ${ }^{22}$. Los primeros son claramente - se anuncien como se anuncien- dictaduras que niegan el derecho fundamental de libertad de conciencia y hacen caso omiso de la Declaración Universal de Derechos Humanos; los segundos y los terceros se encuentran delante de un dilema: no pudiéndose recoger en la legislación de ningún país la serie completa de posibles objeciones de conciencia, ¿deben mencionarse algunas, o es preferible dejar la solución prácti-

${ }^{21}$ La doctrina no ha dejado de recoger toda clase de referencias a la nueva «Filosofía "positivista" que reconozca únicamente lo fáctico y no admita el reino ni la categoría de "valor"... La experiencia del nazismo, y del resto de los totalitarismos, había probado fehacientemente a donde conducían las doctrinas que vaciaban de contenido el concepto de "ley natural" y de "dignidad humana" al hacerla selectiva» (E. Nasarre Goicoechea, El Cristianismo en la construcción europea, Ateneo Jovellanos de Gijón, 2010, p. 20).

${ }^{22} \mathrm{Al}$ menos aproximativamente, y en especial por lo que hace a los dos últimos modelos, cabe pensar en una relación entre el trato dado a la objeción y en general a los derechos relacionados con la libertad religiosa, y los tres modelos de Estados que $\mathrm{S}$. Ferrari señala a tenor de sus relaciones con las Confesiones: «The tradicional approach to the subject of the relations between States and religious faiths starts off from the identification of three distinct models: a) systems based on the conclusion of concordats and agreements betwenn States and religious faiths; b) systems characterised by a State Church, a National Church or a constitutionally recognized "dominant religion"; c) systems where there is a separation between States and religious faiths» (S. Ferrari, «The European Pattern of Church and State Relations», en Comparatiove Law, 20, Nihon University, Tokio 2003, p. 1). 
ca a la interpretación administrativa o judicial de la norma y de las situaciones conflictivas que puedan presentarse en el marco de la misma?

\section{LA OBJECIÓN DE CONCIENCIA ANTE EL DERECHO}

\subsection{El reconocimiento normativo de la objeción}

La doctrina señaló en su día tres posibles tomas de postura del poder político ante la objeción de conciencia: la indiferencia, el contraste y la convergencia ${ }^{23}$. Empecemos aquí por señalar lo que consideramos un evidente presupuesto: no cabe recoger en la legislación de ningún país todas las posibles hipótesis de objeción; éstas son tantas como códigos éticos puede adoptar como propios cada persona, y la apertura de la legislación a todos ellos sumiría en el caos al propio Estado y aún a la sociedad civil. Como acertadamente se tituló, hace ya más de veinte años, un Congreso celebrado en Módena en 1990 — «L'obiezione di coscienza tra tutela della libertà e disgregazione dello Stato democratico» ${ }^{24}$ _ , la actual constante multiplicación de los supuestos de objeción — si se aceptara la pretensión de que el Estado democrático se muestre sensible a todos ellos, a todas las posibles exigencias de la conciencia individual - nos conduciría a una difícil situación: «la multiplicación fáctica de los supuestos de objeción y del número de ciudadanos que desean acogerse a los mismos, junto con la exigencia - que gana cada día terreno tanto en la doctrina jurídica como en la opinión públicade que el estado verdaderamente democrático se muestre sensible a las exigencias de la conciencia individual frente a la excesiva rigidez de las normas, están situando a los poderes públicos ante un auténtico callejón sin salida» ${ }^{25}$.

No es menos clara la idea de que «ante el Estado, las objeciones de conciencia suponen la confrontación de dos realidades jurídicas merecedoras de protección. De un lado, la libertad de conciencia, que se reconoce en la Constitución o en cartas de derechos fundamentales, y cuyo claro exponente —en muchos casos, extremo- representa la objeción. De otro, el cumplimiento de la norma jurídica y de los intereses subyacentes en ella, y la preservación de una comunidad basada en el orden social que supone la decisión democráticamente adoptada por la mayoría» ${ }^{26}$.

${ }^{23} \mathrm{R}$. Bertolino, «La libertad de conciencia: el hombre ante los ordenamientos estatales y confesionales», en Anuario de Derecho Eclesiástico del Estado, III, 1987, p. 42.

${ }^{24}$ VV.AA., L'obiezione di coscienza tra tutela della libertà e disgregazione dello Stato democratico. Atti del Congresso di Studi, Modena 30 novembre - 1º dicembre 1990, a cura di R. Botta, Giuffrè, Milano 1991.

${ }^{25}$ M.J. Ciáurriz, «Objeción de conciencia y Estado democrático», en Anuario de Derecho Eclesiástico del Estado, XII, 1996, pp. 43-44.

${ }^{26}$ R. Navarro-Valls, J. Martínez-Torrón, ob. cit., p. 35. 
Siendo de todo punto o bien injusto o bien impracticable tratar de resolver el tema por las dos vías extremas del rechazo absoluto o de la admisión sin límites de la objeción ${ }^{27}$, ha resultado necesaria la búsqueda de una conjunción entre la vigencia y el respeto de la normativa jurídica y las exigencias derivadas de la oposición de las conciencias a cumplir con esa misma legislación, cuando se la considera objetable desde un punto de vista moral; no parece darse otra vía para resolver la tensión entre ley y conciencia a la que se ha hecho referencia más $\operatorname{arriba}^{28}$.

En esta línea, la Unión Europea reconoció la objeción de conciencia ${ }^{29}$ como un derecho fundamental en el art. 10.2 de su Carta de Derechos Fundamenta$\operatorname{les}^{30}$, a cuyo tenor se garantiza «el derecho a la objeción de conciencia de acuerdo con las leyes nacionales que regulen su ejercicio»; un texto que marca al efecto, con el uso de la expresión «leyes nacionales», el dato de que corresponde a los Estados regular tal derecho y establecer su extensión y los límites que puedan resultar adecuados. Es un gran tema que afecta tanto a los derechos personales como a los derechos de las Confesiones, que marcan a sus miembros aquellas normas doctrinales que les hacen entrar en conflicto con la legislación estatal $^{31}$.

La mención de los límites de la libertad —ninguna libertad y ningún derecho resultan ser absolutamente ilimitados, ni siquiera el derecho a la vida- supone una clara referencia al evidente, y necesario, poder de control del Estado; un

${ }^{27}$ G. Escobar Roca señala como ha sido mayor el esfuerzo de la doctrina por justificar las objeciones que por negar su legitimidad (ob. cit. p. 86).

28 «Apenas acaba el Estado moderno de autoproclamarse neutro desde un punto de vista moral, renunciando a toda inspiración externa y aceptando amoldar su ordenamiento a los principios de una ética universalmente aceptada, cuando se ha visto sometido a una tremenda tensión, que amenaza hoy corromper la aparente solidez de su estructura (...). En este campo nos encontramos con el tema de la objeción de conciencia. Esta aparece como un choque frontal con el concepto actual del Estado neutro: frente a tal neutralidad, he aquí que la conciencia reclama sus fueros» (A. de la Hera, «Sobre la naturaleza jurídica de la objeción de conciencia», en I.C. Ibán (coord.), Libertad y derecho fundamental de libertad religiosa, Edersa, Madrid 1989, pp. 145-146).

${ }^{29}$ En G. Escobar Roca, ob. cit. pp. 155 ss., pueden verse varias otras referencias a la doctrina del Consejo de Europa sobre la objeción.

${ }^{30}$ Vid. sobre la misma T. Freixes, J.C. Remotti, Construcción europea y derechos fundamentales, MINIM, Valencia 2002.

31 «Relations between church and state determine the scope of religious freedom and equality, primarily of religious groups and secondarily of their followers» (K. N. Kyriazopoulos, «Church and State in Modern Europe», en Encyclopedia of religious freedom, Catharine Cookson editor, 2003, p. 56). Es obvio que, en esta cita, la palabra «secundariamente» no indica una menor categoría de los derechos individuales frente a los colectivos, sino que hace referencia a las Confesiones como titulares de las relaciones con los Estados. 
poder que se concreta, en la mayoría de los textos legales y doctrinales, en el «orden público, único límite constitucionalmente reconocido ${ }^{32}$ al derecho de libertad religiosa ${ }^{33}$. Lo que de nuevo nos conduce al Estado como la entidad a la que toca determinar la fijación y extensión del derecho a la objeción de conciencia, con la carga de dificultades y responsabilidad que ello conlleva. Sin que deba olvidarse que, aunque la objeción no provenga necesariamente de fuentes religiosas, las Confesiones y sus miembros figuran entre las entidades y personas con mayor grado de interés e incidencia en este terreno, y en tal medida aquella constituye - como acabamos de indicar- un tema habitual en el campo de las relaciones Estados-Confesiones, de las que dependen la libertad y la igualdad como a un tiempo derechos personales y principios del ordenamiento jurídico ${ }^{34}$.

\subsection{La tutela del derecho a la objeción de conciencia}

Y la primera pregunta que entonces se plantea no es la de la existencia del derecho a la objeción — que no se discute, al margen de la medida en que pueda ser reconocido- , sino la relativa a la tutela de aquel por parte del poder políti$\mathrm{Co}^{35}$. El tema radica en interrogarnos acerca de si existe lo que llamamos un derecho general a la objeción de conciencia; la cuestión no es tanto determinar si el mismo ha de admitirse sino más bien señalar sus límites, lo que se concreta en la afirmación de que, «incluyendo a la objeción de conciencia en el catálogo de los derechos fundamentales», su ejercicio «no puede quedar limitando tan sólo a las concretas modalidades amparadas y reguladas por la ley»; toca entonces a los jueces efectuar «una ponderación de los bienes jurídicos en conflicto (dictamen ético versus norma externa) cuando el sujeto singular elude el cumplimiento de un deber jurídico por razones de conciencia» ${ }^{36}$. Y ello porque la tutela o no de cada objeción ha de encontrar un cauce adecuado y justo en vista de los diferentes ca-

${ }^{32}$ Aquí la referencia es, como resulta claro, al Derecho español vigente.

${ }^{33}$ A. López-Sidro, «Criterios de inscripción en el registro de entidades religiosas según la Sentencia del Tribunal Constitucional de 15 de febrero de 2001», en Derecho y Opinión, 9, Universidad de Córdoba 2001, p. 330.

${ }^{34} \mathrm{~A}$ cuyos efectos ha de recordarse algo ya señalado, que «teniendo en cuenta la limitabilidad general de la libertad religiosa, no todas las reivindicaciones en ella fundadas son atendibles» (A. Barrero Ortega, ob. cit., p. 29).

${ }^{35}$ Sobre el deber de protección de Estado frente a los derechos fundamentales, y en concreto a la libertad religiosa, vid. A. Barrero Ortega, La libertad religiosa ..., cit., pp. 132-135.

${ }^{36}$ R. Navarro-Valls, «Las objeciones de conciencia», en J. Ferrer Ortiz (coord.), Derecho Eclesiástico del Estado español, $5^{\text {a }}$ ed., Eunsa, Pamplona 2004, p. 150. 
sos y supuestos reales en los que el problema o el enfrentamiento entre conciencia y norma pueden plantearse ${ }^{37}$.

No es, pues, cuestión de denegar toda objeción de conciencia, sino de la imposibilidad, no sólo de reflejar todas sus posibles variantes en el ordenamiento, sino incluso de tomarlas en consideración una por una y todas, como supuestos normativamente enumerados y aceptados de incumplimiento de la ley; esto conduciría, en efecto, a la disgregación bien del propio Estado bien del orden jurídico $^{38}$. Al legislador le toca regular de facto, para a un tiempo protegerlos y señalarle límites, determinados supuestos, dígase los más habituales, como suelen ser p. e. la objeción al servicio militar, al aborto o a determinados tratamientos médicos; fuera de esto, la interpretación del ordenamiento, en su aplicación a casos concretos no contemplados específicamente en la legislación, le corresponde normalmente a la jurisprudencia, a la que toca asimismo decidir, en los supuestos legalmente individualizados, si concurren caso por caso, o no, las circunstancias que introducen a una objeción fáctica en el marco de la legalidad.

El juego normativa ética-normativa legal no es por tanto fácil, ya que han de salvarse a la vez la libertad del individuo y el orden jurídico, los derechos fundamentales de la persona y los derechos del poder político en la regulación del orden social ${ }^{39}$. Y sería un error decantarse por uno de los dos polos en detrimento del otro; de ahí lo delicado del tema, y la necesidad, en la que coinciden cuantos tratadistas se han ocupado de la objeción, de ir examinando supuesto por supuesto todas las variedades de la misma, a fin de determinar, por una parte, en qué medida se trata de supuestos protegibles, y por otra en qué grado están los mismos realmente protegidos en cada ordenamiento jurídico nacional o en el internacional; una necesidad y a la vez un desafío para el legislador, toda vez que le

${ }^{37}$ Como ha escrito J.M. Porras Ramírez, a propósito de la objeción de conciencia en el terreno educativo, «la oportuna ponderación de los bienes jurídicos protegidos requiere equilibrar la exigencia, establecida por la ley, que impone el deber básico de estudiar todas las materias que integran la etapa formativa obligatoria, con la previsión, efectuada, también, por la propia norma, que ordena tener en cuenta las características particulares que presentan los estudiantes, mandando respetar sus convicciones y creencias» (Libertad religiosa, laicidad y cooperación con las Confesiones en el Estado democrático de Derecho, Thomson-Civitas, Cizur Menor 2006, p. 145).

38 «È altresì evidente che se si ritenese l'obiezione di coscienza una diretta emanazione del diritto di libertà religiosa, nessun obbligo di conversione sarebbe necessario, poiché saremmo di fronte a un diritto soggettivo, tutelato cioè dall'ordinamento in tutte le sue possibili manifestazioni. L'obiezione di coscienza, invece, va ricondotta ai doveri costituzionali e in quest'ambito deve essere riguardata, facendo attenzione però, anche per rispondere a una pretesa democraticità dell'ordinamento o a un pluralismo malamente inteso, che non si finisca con l'estendere indefinitamente l'istituto» (M. Tedeschi, Manuale di diritto ecclesiastico, Giappichelli, Torino 1998, p. 158).

39 «Es evidente que las actividades de un Estado, en particular la intervención en la esfera individual, está limitada por derechos fundamentales» (R. Arnold, ob. cit., p. 74). 
es muy difícil a la norma cubrir en tiempo y con justicia todas las crecientes exigencias que la realidad no cesa de dar a luz ${ }^{40}$.

Al responder negativamente a la primera de las dos interrogantes que habíamos dejado planteadas - ¿cabe recoger en la legislación de un Estado la totalidad de las posibles objeciones de conciencia? — hemos sentado las bases para responder a la segunda: ¿deben recogerse en el ordenamiento los casos más señalados, o resulta preferible limitarse a garantizar la libertad de conciencia sin descender a la regulación normativa de ningún modelo de objeción? Aquí las opiniones son varias y divergentes; parece conveniente lo primero, en tanto que establecer un modelo de situación jurídica determinada y protegida supone prestar a los futuros intérpretes de la norma una base más firme para el caso de que deban extender la garantía a otras situaciones similares; pero no es menos cierto que, al mismo tiempo, muchas veces la enumeración legal de supuestos concretos tiende a ser considerada como excluyente de todo lo no expresamente tomado en consideración.

\section{LAS OBJECIONES DE CONCIENCIA ANTE EL DERECHO ESPAÑOL}

\subsection{La tutela de la objeción en el actual sistema constitucional}

A este respecto, conviene, para el caso español, tomar en cuenta la actitud adoptada por nuestro Tribunal Constitucional al plantearse la posibilidad de admitir y proteger, o no, supuestos de objeción no contemplados de forma expresa en el ordenamiento ${ }^{41}$.

A tal efecto, ha de señalarse que la Constitución española de 1978 solamente contempla un único tipo de objeción de conciencia, el relativo al servicio mi-

${ }^{40}$ En este campo, «asistimos a una eclosión de un problema bastante habitual en nuestras sociedades democráticas..., el desfase entre la conciencia social y la legalidad vigente» (V. Reina, «Prólogo» a J. Camarasa, Servicio militar y objeción de conciencia, Madrid 1993, p. 11).

${ }^{41}$ Los tribunales españoles han tenido que manifestarse con frecuencia, en los últimos tiempos, sobre diversos derechos relacionados con la libertad religiosa. Sus criterios han sido tantas veces tan variables que no es tarea fácil la de establecer una unidad jurisprudencial sobre ninguno de los puntos sometidos a sus decisiones. En algún caso ha podido decirse que su doctrina ha favorecido, incluso en la totalidad o amplísima mayoría de los casos, a la libertad religiosa: «a la hora de resolver el conflicto entre el derecho a la libertad de expresión y el de libertad religiosa, en la mayoría de los casos estudiados — en realidad en todos ellos, con la excepción sólo de la aludida sentencia del Tribunal Supremo de 25 de enero de 1983 - los tribunales han estimado, directa o indirectamente, la existencia de violación del derecho de libertad religiosa» (D. García-Pardo, «La protección de los sentimientos religiosos en los medios de comunicación», en Ius Canonicum, 79, 2000, p. 155); pero esto no es lo común. 
litar, al que se refiere el artículo 30.2 del texto constitucional: «La ley fijará las obligaciones militares de los españoles y regulará, con las debidas garantías, la objeción de conciencia, así como las demás causas de exención del servicio militar obligatorio.... ${ }^{42}$. Mientras tal servicio estuvo en vigor, una Comisión Nacional de Objeción de Conciencia, radicada en el Ministerio de Justicia, valoró las correspondientes solicitudes y determinó la toma o no en consideración de las objeciones presentadas. Pero a partir del momento en que la obligatoriedad del servicio militar quedó en suspenso — desde el 31.XII.2001, a tenor de la Ley 17/1999 de 18 de mayo- esta objeción perdió su razón de ser, y se encuentra en la misma situación que el deber de prestar aquel servicio.

¿Supone ello que ninguna otra objeción de conciencia puede tener acogida en España? Se han presentado en la realidad bastante otras, y a tal efecto, como indicábamos, hay ante todo que atender a la actitud adoptada al respecto por el Tribunal Constitucional. Éste se ha pronunciado en varias importantes sentencias llamadas a tener una amplia acogida en la doctrina-, y que no resultan coherentes entre sí, tanto que se ha dicho con razón que, en este campo, la jurisprudencia constitucional «ha seguido una línea errática y en ocasiones contradictoria» ${ }^{43}$.

En efecto. En sus sentencias $160^{44}$ y $161 / 87^{45}$, de 27 de octubre, el Alto Tribunal se planteaba el interrogante de la posibilidad o no de un derecho general a la objeción de conciencia; en la primera de ambas se establece lo siguiente, en relación la objeción al servicio militar: ésta es aceptada porque así lo establece el artículo 30 de la Constitución, «en cuanto que sin ese reconocimiento constitucional no podría ejercerse el derecho, ni siquiera al amparo de la libertad ideológica o de conciencia, que, por sí mismo, no sería suficiente para liberar a los ciudadanos de deberes constitucionales o "subconstitucionales" por motivos de conciencia». Y, en la segunda sentencia, se sostiene que «la objeción de conciencia con carácter general, es decir, el derecho a ser eximido del cumplimiento de los deberes constitucionales o legales por resultar ese cumplimiento contrario a las propias convicciones, no está reconocido ni cabe imaginar que lo estuviera en nuestro Derecho o en derecho alguno, pues significaría la negación misma de

${ }^{42} \mathrm{CE}$, art. 30: «1. Los españoles tienen el derecho y el deber de defender a España. 2. La ley fijará las obligaciones militares de los españoles y regulará, con las debidas garantías, la objeción de conciencia, así como las demás causas de exención del servicio militar obligatorio, pudiendo imponer, en su caso, una prestación social sustitutoria. 3. Podrá establecerse un servicio civil para el cumplimiento de fines de interés general. 4. Mediante ley podrán regularse los deberes de los ciudadanos en los casos de grave riesgo, catástrofe o calamidad pública».

${ }^{43}$ L. Prieto Sanchis, ob. cit., p. 80.

${ }^{44}$ Vid. en Anuario de Derecho Eclesiástico del Estado, IV, 1988, pp. 670-703.

${ }^{45}$ Vid. en Anuario de Derecho Eclesiástico del Estado, IV, 1988, pp. 703-714. 
la idea de Estado» ${ }^{46}$. Una doctrina que ha sido calificada de errónea ${ }^{47}$, puesto que con ella el Tribunal parece que se inclina por rechazar incluso la posibilidad de que cualquier objeción no reconocida expresamente por el ordenamiento pueda ser objeto de tutela jurídica ${ }^{48}$.

Este segundo texto, de la sentencia 161/1987, contiene -como su simple lectura muestra - las siguientes importantes afirmaciones: a) que no solamente los deberes nacidos de un precepto directamente constitucional, sino también los procedentes de una norma de menor rango, resultan de tal modo obligatorios que en ningún caso — salvo expreso reconocimiento al propósito en el ordenamiento- pueden incumplirse invocando la objeción de conciencia; y que, b) no solamente una objeción de conciencia de tipo general — no establecida de modo expreso en la legislación - queda fuera de nuestro Derecho, sino que, c) ni siquiera cabe imaginar su hipotética admisión, la cual, d) destrozaría incluso a la idea de Estado.

Es difícil imaginar una actitud más legalista, más intransigente, en mayor medida coartadora de la libertad personal ${ }^{49}$. El Tribunal opta por prohibir toda objeción no expresamente contenida en las leyes, atribuyendo al Estado el monopolio de la conciencia, la capacidad de indicar al ciudadano los casos en que puede seguir los dictámenes de su conciencia y aquéllos en que no. Tanto más cuanto que no es cierto que con el ejercicio de la libertad se niegue la idea de Estado, y ni siquiera la de orden público; la disgregación del Estado provendría de la absoluta eficacia jurídica de cualquier objeción en cualquier caso, no de la determinación por parte de la jurisprudencia de en qué casos no expresamente determinados en el ordenamiento hay que decantarse por la libertad en conflicto con la ley, por deducirse el modo específico de ejercicio de esa libertad, en el caso concreto, de la garantía general que el Derecho ha de ofrecer a los derechos fundamentales de la persona.

Que es justamente lo que el propio Tribunal Constitucional —de ahí la sorpresa que causa la doctrina sentada en 1987 — había establecido en una sentencia de 1982, y más específicamente en otra de 1985. En la primera, de 23 de

${ }^{46}$ Vid. al respecto M. R. León Benítez, M. M. Leal Adorna, Derecho y factor religioso, Delta, Madrid 2009, pp. 215-216.

${ }^{47}$ L. Prieto Sanchis, ob. cit., p. 82.

${ }^{48}$ Ya R. Bertolino, en su «La libertad de conciencia», cit., p. 73, señala a este respecto cómo la progresiva ampliación de la esfera estatal está dando lugar en nuestro tiempo a una multiplicación y a una mutación cualitativa de las decisiones e intervenciones legislativas, lo cual opera siempre a costa de las libertades personales.

49 «Como consecuencia del deber del Estado de garantizar el libre ejercicio de la libertad de religión y de creencia, los poderes públicos están obligados a procurar una adapación razonable a los deberes de conciencia de los ciudadanos, en la medida en que no se perjudique un interés público predominante» (R. Navarro-Valls, J. Martínez-Torrón, ob. cit., p. 62). 
abril ${ }^{50}$, de modo general se estableció que «puesto que la libertad de conciencia es una concreción de la libertad ideológica... puede afirmarse que la objeción de conciencia es un derecho reconocido explícita e implícitamente en la ordenación constitucional española», con clara referencia de un lado al servicio militar regulado en el artículo $30 \mathrm{CE}$, y de otro al contenido de la libertad ideológica y religiosa garantizadas en el art. 16 CE. Y seguidamente, en la sentencia 53/1985, de 11 de abril ${ }^{51}$, relativa a la objeción al aborto, que no se regula en nuestra legislación, figuran estas palabras: «Por lo que se refiere al derecho a la objeción de conciencia... existe y puede ser ejercido con independencia de que se haya dictado o no tal regulación. La objeción de conciencia forma parte del contenido del derecho fundamental a la libertad ideológica reconocido en el art. 16.1 CE y, como este Tribunal ha indicado en diversas ocasiones, la Constitución es directamente aplicable, especialmente en materia de derechos fundamentales».

Tesis ésta mucho más coherente con los valores generales del ordenamiento fijados en el art. $1 \mathrm{CE}$ y con el derecho fundamental garantizado en el art. $16 \mathrm{CE}$, ya que, si se vacía de contenido a la libertad — reduciéndola a los límites estrictos de los supuestos expresamente recogidos en la legislación-, el poder político se transforma en la fuente única y exclusiva de la justicia, lo que ha sido un denominador común de todos los regímenes dictatoriales de la historia. La justicia deja así de ser — como la califica el art. 1.1. CE- un valor superior del ordenamiento que ha de inspirar al mismo, para degenerar en un valor cuyo contenido es fijado por el propio ordenamiento, al que ya no inspira sino que de él procede $e^{52}$.

$Y$ es en este contexto como tiene validez la afirmación, antes mencionada a partir de algunas citas doctrinales, de que tocará a los tribunales determinar en qué casos concretos ha de operar la objeción de conciencia, en el juego de la coherencia entre la fuerza de la ley y el valor de la libertad. Sin embargo, es evidente que el tema no es simple, y que caben diferentes posturas por parte de los especialistas al tratar de encontrar para el mismo una postura científica satisfactoria.

Partimos de que las dos posiciones indicadas del Tribunal Constitucional son «difícilmente conciliables» ${ }^{33}$. La admisión de «la objeción como una concreción

${ }^{50}$ Vid. J.A. Souto Paz, «Jurisprudencia del Tribunal Constitucional», en Anuario de Derecho Eclesiástico del Estado, I, 1985, pp. 476-477.

${ }^{51}$ Vid. J.A. Souto Paz, «Jurisprudencia del Tribunal Constitucional», en Anuario de Derecho Eclesiástico del Estado, II, 1986, p. 521.

${ }^{52}$ La doctrina no ha dejado de señalar el deber del Estado de respetar determinadas instancias superiores a su derecho; la justicia no la determina el Estado sino que supone un valor previo de orden superior (vid. R. Bertolino, L'obiezione di coscienza «moderna». Per una fondazione costituzionale del diritto di obiezione, Giappichelli, Torino 1994, pp. 43 ss.).

53 I. Martín Sánchez, «Algunos supuestos controvertidos de objeción de conciencia», en I. Martín Sánchez, M. González Sánchez, Algunas cuestiones controvertidas del ejercicio del derecho fundamental de libertad religiosa en España, Fundación Universitaria Española, Madrid 2009, p. 234. 
de la libertad ideológica» y la consiguiente «posibilidad de su alegación directa sin necesidad de desarrollo legislativo ${ }^{54}$, junto con la posterior negativa a aceptar ningún tipo de objeción no tipificado legalmente ${ }^{55}$, isignifican — como se ha preguntado la doctrina ${ }^{56}$ - que el Tribunal redujo en 1987 el sentido de sus decisiones anteriores a sólo el caso del aborto y no a otros supuestos? O ¿tal vez hay que interpretarlas como que la sentencia de 1987 es la regla general y las de 1982 y 1985 se refieren a manifestaciones específicas de la objeción? Y, «si se considera la objeción de conciencia como un derecho constitucional autónomo el cual requiere por tanto una ley específica para su ejercicio-, resulta difícil admitir que, como ha afirmado el Tribunal Constitucional, algunas de sus manifestaciones sean una concreción de las libertades reconocidas en el artículo 16,1 de la Constitución y por ello, al tener la naturaleza de un derecho fundamental, sean alegables directamente» ${ }^{57}$. En último término, al interpretar las afirmaciones hechas por el Tribunal Constitucional en 1987, se hace necesario considerar que resulta inaceptable sostener que ninguna objeción puede tutelarse fuera de las especialmente establecidas en el ordenamiento; esto equivaldría a definir que el Estado no «garantiza» la libertad de pensamiento, de conciencia y de religión, sino que la crea, y donde no aparece la misma «creada» en el ordenamiento es que no existe ${ }^{58}$.

Toca, pues, no al legislador determinar el contenido del derecho a la objeción, sino a los jueces analizarlo y reconocerlo en los casos en que proceda; es la única verdadera tutela jurídica de las objeciones si no exigimos ni que estén todas sin distinción reconocidas, ni que solamente tengan vigor las que hayan sido objeto de un específica regulación normativa.

Bastan sobradamente estas indicaciones para señalar la extrema dificultad del tema y la diversidad de los pareceres que lo acompañan. Y, a efectos de lo que aquí debe desarrollarse, será necesario pasar de estas consideraciones doctrinales a la efectiva presencia en el ordenamiento jurídico y en la vida social española de los diversos supuestos de objeción de conciencia, y al tratamiento que los mismos han recibido por parte de nuestro Derecho en orden al mantenimiento del orden público y a la garantía de los derechos fundamentales. Un tratamiento complejo en la medida en que, como ha quedado indicado, se han ido multiplicando los

${ }^{54}$ I. Martín Sánchez, ob. y lug. cit.

${ }^{55}$ Lo que ha sido calificado como una doctrina general «errónea» (L. Prieto Sanchis, ob. cit., p. 82).

${ }^{56}$ C.M. Romeo Casabona, El Derecho y la Bioética ante los límites de la vida humana, Madrid 1994, pp. 131-132, cit. por I. Martín Sánchez, ob. cit., p. 235.

${ }^{57}$ I. Martín Sánchez, ob. cit., p. 235.

58 Se ha señalado al efecto cómo las objeciones de conciencia, antes que ser secundum legem, como nacidas de la misma, son secundum ius, idea que apunta con acierto al carácter superior al Estado de la libertad y la ética (vid. R. Bertolino, Obiezione di coscienza, cit., p. 94). 
supuestos de objeción, que constituyen hoy un fenómeno presente «en todas las facetas de la vida humana en las que éste se puede plantear, facetas que cada día son más numerosas. En efecto, problemas como la eutanasia, el aborto, las cláusulas de conciencia a la información, la negativa de los Testigos de Jehová a recibir transfusiones de sangre, el trasplante de órganos, etc., han sensibilizado a la opinión pública, a la doctrina y a la jurisprudencia, que pugnan por encontrar una solución respetuosa con los distintos intereses en liza» ${ }^{59}$.

\subsection{La única objeción de conciencia expresamente mencionada en la Constitución de 1978: el servicio militar}

No se trata por supuesto de la primera objeción de conciencia a lo largo del tiempo, pues antes de que en el siglo XIX comenzase a hablarse de ella ya el hombre había conocido muchos casos - por lo común dramáticos- de oposición al cumplimiento de las leyes en nombre de la conciencia. El ejemplo de los tres siglos de persecuciones a los cristianos bajo el Imperio Romano, por negarse a rendir culto al Emperador, no es ni mucho menos único, pero puede resultar paradigmático ${ }^{60}$. De hecho, la historia ha conocido muchos otros casos, unidos en su mayor parte por un constante rechazo de la objeción y el correspondiente castigo de los objetores.

En el XIX se comienza sin embargo a hablar y tratar de la objeción militar en un contexto ya abierto a las libertades, que entran en la vida jurídica y constitucional de las naciones a partir de las declaraciones sobre derechos humanos surgidas a raíz de la Revolución francesa y de la independencia de los Estados Unidos. Esta objeción a la prestación de deberes militares, la primera en aparecer en el marco de los ordenamientos jurídicos de origen democrático, fue curiosamente rechazada en sus inicios por el pensamiento y la política liberales, que se negaban a reconocer relevancia jurídica a la conciencia, que en aquellos momentos sólo era concebida como de origen y motivación religiosos ${ }^{61}$. Con el transcurso de los años, el concepto de la objeción militar cambió de signo, y pasó a ser un acto de rebeldía de los movimientos que, con lenguaje de hoy, podríamos

${ }^{59}$ M.J. Ciáurriz, «La objeción de conciencia», en Anuario de Derecho Eclesiástico del Estado, III, 1987 , p. 269.

${ }^{60}$ No ha dejado de observarse que las persecuciones romanas procedían de un poder político y una sociedad que eran religiosos y no ateos, y poseían valores de origen religioso, a diferencia de lo que hoy sucede cuando el Estado se autoatribuye funciones propias de la religión al rechazar la realidad de la fe y, por tanto, de toda religión (vid. D. Negro Pavón, ob. cit., p. 9).

${ }^{61}$ Vid. A. de la Hera, «Sobre la naturaleza jurídica de la objeción de conciencia», en I. C. Ibán (coord.), Libertad y derecho fundamental de libertad religiosa, cit., p. 144. 
denominar de «izquierdas», frente a la concepción del ejército como un instrumento de poder represivo.

Superadas ya estas desviaciones — que politizaban la objeción en lugar de considerarla una consecuencia del recto uso de la libertad-, la objeción al servicio militar ha sido la más extendida, la que ha calado en mayor número de ordenamientos, y la que en cierto modo ha abierto en el último siglo el camino a los restantes modelos. Sin embargo, hoy en día ha perdido la mayor parte de su significado, a partir de las mutaciones operadas en la obligatoriedad de los deberes militares —al menos en tiempos de paz-; por lo que hace a España, como veremos, en la actualidad resulta ser una objeción inoperante, estando suspendida en su vigor la norma constitucional que establece los deberes militares de todos los españoles.

Sin embargo, su largo protagonismo histórico y, al menos en el caso español, el hecho de ser la única objeción jurídicamente reconocida de modo expreso y regulada como tal en la Constitución, le ha asignado un cierto papel ejemplar, que va desde quienes interpretan que es la única vigente y cierran la puerta a todas las demás, a los que - estimando que toda otra objeción cabe en el derecho de libertad de conciencia y debe ser analizada en cada supuesto a efectos de su eficacia- consideran sin embargo que el modelo de la militar puede encerrar en sí un buen criterio de concepción y comprensión de cualquiera otra. No deja por otro lado de ser interesante observar que, incluyéndose en los Acuerdos, tanto con la Iglesia católica ${ }^{62}$ como con las tres Confesiones minoritarias ${ }^{63}$, el tema del servicio militar de los ministros de culto, y poseyendo esta objeción de conciencia rango constitucional, en ningún caso se la mencione ni aluda en aquellos Acuerdos ${ }^{64}$.

Nada habría que oponer a este lógico argumento, si no fuera porque la objeción al servicio militar posee algunas características específicas que no son trasladables a ninguna otra. Nos referimos al dato de que esta objeción suele ir acompañada — y así sucede en el artículo $30 \mathrm{CE}$ — del posible deber de sustituirla por algún otro tipo de servicio al Estado y a la sociedad, hipótesis no concebible en principio en las restantes; del mismo modo, la ya señalada pérdida de relevancia y oportunidad de esta objeción no permite hoy parangonarla al notable desarrollo de muchas otras — por ejemplo las relacionadas con la bioética, como veremos—; en la hora presente, «pensar en las objeciones de conciencia en

${ }^{62}$ Acuerdo de 3 de enero de 1979, España-Santa Sede, sobre asistencia religiosa a las Fuerzas Armadas y servicio militar de clérigos y religiosos, art. 5.

${ }^{63}$ Arts. 4 de los tres Acuerdos de 1992, con la FEREDE, la FCIE y la CIE.

${ }^{64}$ «El acuerdo es el procedimiento que utiliza el Ejecutivo para elaborar un proyecto de ley en el que se tienen en cuenta las propuestas de las Confesiones» (M. Moreno Antón, «Algunos aspectos controvertidos sobre los Acuerdos de cooperación con las Confesiones religiosas», en Revista Jurídica de Estudiantes, 2, Universidad Autónoma de Madrid, Dykinson, 2000, p. 132). 
términos de objeción de conciencia al servicio militar es empequeñecer el discurso en un tema de amplio respiro y de imprevisibles aplicaciones futuras» ${ }^{65}$.

Referirse a la regulación normativa de esta objeción en el ordenamiento español supone recoger una sucesiva serie de normas, no siempre del todo coherentes entre sí, que marcan un itinerario jurídico cuyos principales pasos son los siguientes. En primer lugar, y sobre todo, el propio texto constitucional de 1978, cuyo artículo 30, en su dos primeros párrafos, establece que: «1. Los españoles tienen el derecho y el deber de defender a España. 2. La ley fijará las obligaciones militares de los españoles y regulará, con las debidas garantías, la objeción de conciencia, así como las demás causas de exención del servicio militar obligatorio, pudiendo imponer, en su caso, una prestación social sustitutoria».

Estamos ante un texto que plantea dos cuestiones: la de determinar qué origen posee esa objeción, de dónde procede; y la de conocer su sucesiva regulación legal, ya que la Constitución deja ésta en las manos de leyes posteriores de desarrollo y aplicación del texto constitucional. No nos detendremos en cambio en analizar - por tratarse de un punto muy debatido entre los especialistas, y que desborda los límites de esta exposición - la opinión de que la llamada objeción de conciencia al servicio militar no es realmente una objeción, ya que no es un caso de conflicto entre la ley y la conciencia, desde el momento en que la norma prevé la posibilidad de incumplir el precepto: estaríamos ante una opción legal y no una objeción, ante lo que se ha denominado opciones de conciencia o soluciones legislativas alternantes.

Por lo que hace a la primera cuestión arriba planteada, el origen de este tipo de objeción, a tenor de la ya citada sentencia del TC 160/1987, la objeción de conciencia no constituye un derecho fundamental, sino un «derecho constitucional autónomo». Ello supone que se considera que la misma no forma parte del contenido del derecho de libertad de conciencia, que sí que es un derecho fundamental. Lo cual es aseverado por otra sentencia del mismo Tribunal, la $321 / 1994$, de 28 de noviembre ${ }^{66}$, según la cual objeción de conciencia y derecho fundamental de libertad son realidades distintas, de modo que «el derecho a ser declarado exento del servicio militar no viene directamente del ejercicio de la libertad ideológica, por más que se encuentre conectado con el mismo, sino tan sólo de que la Constitución en su art. 30.2 expresamente ha reconocido el derecho a la objeción de conciencia», lo que es evidente que supone cerrar la puerta a todas las restantes objeciones, no reconocidas en la Constitución y que tan sólo de la libertad de conciencia pueden tomar su origen.

Por lo que hace a la regulación legal, se sucedieron en España una serie de normas destinadas a configurar la misma y que resulta superfluo detallar aquí, dada la

\footnotetext{
${ }^{65}$ R. Navarro-Valls, J. Martínez-Torrón, Conflictos entre Conciencia y Ley, cit., p. 74.

${ }^{66}$ Vid. en Anuario de Derecho Eclesiástico del Estado, XI, 1995, pp. 477-481.
} 
no vigencia del tema desde el año $2001^{67}$. Baste indicar que se estableció por ley en 1984 la prestación social sustitutoria prevista por el art. $30.2 \mathrm{CE}^{68}$, y que con el tiempo muchos objetores se negaron incluso al cumplimiento de tal deber, alegando que someterse a él era una forma de legitimar la obligatoriedad del servicio militar y la imposibilidad de eludirlo en cualquiera de sus manifestaciones ${ }^{69}$. El tema está hoy por hoy cerrado - al menos mientras subsista la suspensión del servicio militar obligatorio- - si bien se han dado algunos casos, muy poco significativos, de abandono de la profesión militar, alegando motivos de conciencia, cuando tal profesión es asumida con el claro propósito de desertar a renglón seguido, a efectos de crear situaciones de insumisión que redunden en desprestigio de las Fuerzas Armadas. El supuesto existe, pero parece lejos de podérsele tomar en cuenta como una manifestación de la objeción de conciencia, aparezca ésta como parte del contenido de la libertad o tan sólo como derecho derivado de una norma constitucional.

\subsection{Las objeciones de conciencia en el ámbito biológico}

En el campo de la moderna biología se nos ofrece hoy una muy variada gama de posibilidades de conflictos entre la libertad de conciencia y las nuevas vías de actuación biomédica o bioética, a que el actual desarrollo de la ciencia está dando lugar. De un lado, se trata de problemas relacionados con un tema tan capital como lo es el del aborto; de otro, de dificultades surgidas a partir de la oposición de algunas confesiones religiosas - y en consecuencia de sus miembrosa la utilización de determinados tratamientos médicos; de otro, del recurso a nuevas técnicas reproductivas, hasta ahora desconocidas; de otro aún, de la serie de problemas que conllevan consigo la muerte voluntaria y la reciente sustitución del protagonismo del médico por el del enfermo en la toma de decisiones con relación a la salud y la vida ${ }^{70}$; en fin, ha de incluirse en este punto la ya aludida ob-

${ }^{67}$ Vid. J. Oliver Araujo, La objeción de conciencia al servicio militar, Editorial Civitas, Madrid 1993, con amplias referencias legislativas y bibliográficas.

${ }^{68}$ Vid. A. Millán Garrido, Objeción de conciencia y prestación social, Editorial Trivium, Madrid 1992, que se ocupa específicamente de dicha normativa.

${ }^{69}$ Tuvieron lugar diversos recursos de inconstitucionalidad contra diversos aspectos de la citada ley de objeción: vid. en M. Ramos Morente, La objeción de conciencia, Área de Juventud del Ayuntamiento de Málaga, Málaga 1990, p. 27.

${ }^{70}$ Una visión de conjunto y una exposición detallada de toda esta temática, con relación a los grandes problemas bioéticos y a la actitud ante los mismos de las principales Confesiones religiosas, puede vid. en M. J. Ciáurriz, «La Declaración Universal de Bioética y Derechos Humanos y el Pluralismo Religioso», en H. Gros Espiell, Y. Gómez Sánchez (coords.), La Declaración Universal sobre Bioética y Derechos Humanos de la UNESCO, Editorial Comares, Granada 2006, especialmente en los epígrafes «La aportación de las Confesiones religiosas a la elaboración de la Declaración» (pp. 82-86) y, en especial, «Confesiones religiosas y Bioética» (pp. 87-117). 
jeción de conciencia farmacéutica, en cuanto que los profesionales de la farmacia pueden verse también en el caso de contradecir o no a su conciencia al corresponderles el facilitar a los ciudadanos determinados medios destinados a contribuir a la realización de prácticas abortivas o contrarias a la fecundación

\subsubsection{El aborto}

Probablemente, una vez desplazada de su anterior posición preeminente la objeción militar, sea hoy la objeción de conciencia al aborto la que ocupe el primer lugar tanto por su incidencia social como por la atención que le vienen prestando a un tiempo los poderes públicos y la doctrina.

Si en 1992 podía ya afirmarse que la legislación sobre el aborto había creado en España una situación abierta a no pocos conflictos de conciencia, y generadora de una cada vez más extensa bibliografía, y que aquel proceso tendía a agravarse - «el paso del tiempo, y la aprobación y entrada en vigor de la reforma... no solamente no han mejorado esta situación, sino que incluso la han agravado» ${ }^{71}$ - , puede hoy decirse que la sucesiva legislación no ha contribuido ciertamente a descomplicar el tema. La cada vez más ampliada despenalización o permisión del aborto nos obliga en efecto a tratar de determinar quien es el titular del derecho a este tipo de objeción y en qué casos puede la misma ser ejercida como un derecho.

Por lo que hace al primer punto, la gran mayoría de la doctrina estima que el objetor al aborto es el personal sanitario; la mujer desea abortar en el ejercicio de un derecho a ello que la ley le reconoce, y el médico - y el resto de sus colaboradores - se niega a intervenir por motivos de conciencia: su conciencia rechaza el aborto. En cuanto que la mujer se mantiene dentro de la ley y el personal sanitario entra en conflicto con ésta, resulta claro quien es el objetor.

Sin embargo, no falta el parecer doctrinal de que la objetora es la mujer. En este caso, se ha dicho ${ }^{72}$, no estamos ante una objeción derivada de la libertad ideológica garantizada en el artículo $16 \mathrm{CE}$ —que llevaría al médico a exigir que se le reconozca bajo tal amparo su derecho a objetar-, sino de una objeción de la mujer a la norma constitucional que impone el derecho a la vida (art. $15 \mathrm{CE}$ ). La mujer entra en conflicto con la norma: ello la convierte en objetora; el médico desea que la norma constitucional se cumpla, que se respete el derecho a la vida: al

${ }^{71}$ M.J. Ciáurriz, «El aborto en el Derecho español. Consideraciones doctrinales y legislativas», en Anuario de Derecho Eclesiástico del Estado, VIII, 1992, p. 99.

${ }^{72}$ J.M. González del Valle, Derecho Eclesiástico Español, Thomson-Civitas, Editorial Aranzadi, Cizur Menor 2005, pp. 302-303. 
negarse a practicar el aborto, se niega a incumplir la ley, «se niega - ha escrito González del Valle ${ }^{73}$ — a ser objetor».

Esta hipótesis solamente podría resultar válida en todos los casos, si no existiese en la legislación supuesto alguno de permisión del aborto. Desde el momento en que la legislación despenaliza, y permite por tanto, varios casos de abortos legales, la idea de la mujer objetora entra en juego exclusivamente en los casos en que ella desea abortar sin protección legal alguna, fuera de todo modelo de aborto permitido. Y dado que la actual permisión del aborto —en base a generalidades e imprecisiones muy graves en su redacción normativa y sobre todo en su aplicación, que como es sabido se está llevando a cabo por clínicas abortistas que de hecho, y ante la pasividad de los poderes públicos, escapan a todo control y verificación de la legalidad de sus actuaciones — ha abierto hasta el límite la posibilidad de abortar presuntamente dentro de la ley; y dado a la vez que la interpretación del tema, que públicamente se ofrece hoy desde medios oficiales responsables de la sanidad, ha tratado de vaciar de contenido al precepto del art. 15 CE sobre quien es el titular del derecho a la vida allí reconocido; dado todo ello, la hipótesis de una mujer que desea abortar contra legem por oponerse al derecho a la vida, y cuyo deseo no está tutelado por la permisividad de la legislación, es de hecho un supuesto puramente especulativo.

Mucha mayor base posee la tesis generalizada de que la objeción de conciencia al aborto es propia del personal sanitario. La mujer desea abortar secundum legem —o cuando menos dentro de la casi ilimitada tolerancia en la interpretación más amplia posible de la ley, pero en todo caso bajo una cobertura legal—; la aceptación por la legislación de supuestos de objeción, que pasan de ir contra la ley a estar protegidos por la misma, es lo que —como sabemos - la doctrina denomina con acierto no ya objeciones sino opciones de conciencia ${ }^{74}$; y entonces, tras esta opción de la mujer, son los miembros del personal sanitario los que aparecen como protagonistas de la objeción, cuando se niegan a participar en el aborto por exigencias de sus criterios éticos, de su conciencia.

Así pues, partimos de considerar que la objeción de conciencia al aborto contiene tanto la negativa a las prácticas abortivas directas como a la cooperación en las mismas, el rechazo de toda participación de cualquier tipo en la realización de los abortos legales ${ }^{75}$; una definición que, como vemos que sucede en general con

${ }^{73}$ J.M. González del Valle, ob. cit., p. 304.

${ }^{74}$ A. González-Varas, Derecho y Conciencia en las profesiones sanitarias, Editorial Dykinson, Madrid 2009, p. 32.

75 «Los supuestos de objeción de conciencia que surjan en el marco de esta legislación [el autor se refiere a la actualmente vigente en España] — incluso los referidos al personal indirectamente implicado en la realización de abortos - tendrán que resolverse acudiendo a la regla de la proporcionalidad» (S. Cañamares Arribas, «Las objeciones de conciencia», en M.A. Jusdado Ruiz-Capillas (dir.), Derecho Eclesiástico del Estado, Colex, Madrid 2011, p. 118). 
la objeción de conciencia —en continuo proceso de difusión y ampliación—, ha de extenderse a diversos supuestos, como pueden ser, p. e., la negativa de los profesionales de la farmacia a dispensar medicamentos destinado a una finalidad abortiva; asimismo, el problema planteado, en el ámbito fiscal, por la actitud de los contribuyentes, en determinados países, que se oponen al pago de aquellos impuestos —o la parte proporcional de los mismos — que el Estado destine a financiar abortos.

Ya se ha aludido líneas arriba a la situación legal de este modelo de objeción en España, a raíz de la ya citada sentencia 53/1985, de 11 de abril. Una primera redacción de la ley que estableció los casos de despenalización del aborto fue aprobada el 30 de noviembre de 1983, y contra la misma se presentó un recurso previo de inconstitucionalidad que dio lugar a la sentencia citada. Y ya sabemos que ésta estableció que, por lo que hace a la objeción de conciencia, ésta «existe y puede ser ejercida con independencia de que se haya dictado o no» una regulación de la misma. Y ello porque «la objeción de conciencia forma parte del contenido del derecho fundamental a la libertad ideológica y religiosa reconocida por el art. 16.1 de la Constitución y, como ha indicado este tribunal en diversas ocasiones, la Constitución es directamente aplicable, especialmente en materia de derechos fundamentales» ${ }^{76}$.

Referidas ya con anterioridad las contradicciones en que incurrió más adelante el TC en relación con esta temática —recuérdese el carácter contradictorio de la doctrina jurisprudencial del TC al respecto, en el que también insiste Souto Paz cuando enfrenta las dos sentencias de 1985 y 1987 ya citadas ${ }^{77}$ - de hecho la primera sentencia dio lugar a una nueva redacción de la ley impugnada, hasta convertirse en la Ley Orgánica 5/1985, de 5 de julio, que durante años reguló el tema del aborto en nuestro ordenamiento. Están contemplados diversos motivos que justifican el aborto —el aborto terapéutico, el eugenésico, el ético-, despenalizados en la correspondiente reforma del Código penal; se alegó luego que tal elenco de causas resultaba insuficiente — según Informe de la Fiscalía General del Estado de 13 de febrero de 1991- y se propusieron el aborto por motivos económicos y la llamada Ley de Plazos, relativa al momento de la gestación dentro del cual el aborto puede incluso resultar discrecional. En todo caso, la objeción no depende de las causas que legalmente se consideren justificativas del aborto, sino de la negativa a practicar abortos por imperativo de conciencia. Y, en la práctica, dentro del marco de la normativa legal de 1985, la objeción de conciencia del personal sanitario se ha visto alegada en numerosos casos por los

\footnotetext{
${ }^{76}$ Vid. en J. A. Souto Paz, «Jurisprudencia del Tribunal Constitucional», en Anuario de Derecho Eclesiástico del Estado, II, 1986, p. 521.

${ }^{77}$ J.A. Souto Paz, Comunidad política y libertad de creencias. Introducción a las Libertades Públicas en el Derecho Comparado, Marcial Pons, Madrid 2007, p. 271.
} 
médicos y demás profesionales implicados en la materia, y la jurisprudencia de los tribunales de diferentes niveles - llamada a determinar la aceptación de tales objeciones - resultó contradictoria y vacilante, según con detalle se ve recogida por la bibliografía ${ }^{78}$.

Esta situación se ha visto alterada al modificarse la regulación legal del aborto mediante una nueva Ley Orgánica, la 2/2010, de 3 de marzo, en la cual la objeción de conciencia aparece expresamente mencionada en su art. 19.2 en los siguientes términos ${ }^{79}$ : «La prestación sanitaria de la interrupción voluntaria del embarazo se realizará en centros de la red sanitaria pública o vinculados a la misma. Los profesionales sanitarios directamente implicados en la interrupción voluntaria del embarazo tendrán el derecho de ejercer la objeción de conciencia sin que el acceso y la calidad asistencial de la prestación puedan resultar menoscabadas por el ejercicio de la objeción de conciencia. El rechazo o la negativa a realizar la intervención de interrupción del embarazo por razones de conciencia es una decisión siempre individual del personal sanitario directamente implicado en la realización de la interrupción voluntaria del embarazo, que debe manifestarse anticipadamente y por escrito. En todo caso los profesionales sanitarios dispensarán tratamiento y atención médica adecuados a las mujeres que lo precisen antes y después de haberse sometido a una intervención de interrupción del embarazo» ${ }^{80}$.

Es obvio que la norma plantea diversas dificultades en su interpretación, al tratarse de un texto sumamente restrictivo y que acepta la objeción en términos mucho más cortos que los postulados por las Comisiones Médicas de Deontología e incluso por diversos organismos internacionales; singularmente es de notar la indefinición contenida en los términos "profesionales sanitarios directamente implicados en la interrupción voluntaria del embarazo», que por otra parte no es el único punto abierto al conflicto interpretativo de la norma. Y no debe dejar de señalarse que, en relación con la misma temática, también está hoy incidiendo la actitud política favorable al aborto en los sistemas y las leyes educativas, referentes tanto a la enseñanza media como universitaria, en clara contraposición con la protección constitucional al derecho de los padres a decidir el tipo de formación religiosa y oral que han de recibir sus hijos (art. 27.3 CE).

Y del mismo modo que, al referirnos a la objeción militar, ha quedado indicado que, una vez reconocida por la Constitución, puede decirse que en realidad estamos ante una solución legislativa alternante ${ }^{81} \mathrm{o}$ ante una opción de concien-

\footnotetext{
${ }^{78}$ L. Prieto Sanchis, ob. cit., pp. 80 y ss.

${ }^{79}$ BOE de 4 de marzo de 2010.

${ }^{80}$ Vid. en I. Martín Sánchez, «El aborto en el sistema jurídico español», en I. Martín Sánchez (coord.), Libertad de conciencia y Derecho sanitario en España y Latinoamérica, Comares, Granada 2010, pp. 316 ss.; S. Cañamares Arribas, «Las objeciones de conciencia», cit., pp. 117 ss.

${ }^{81}$ Vid. G. Escobar Roca, ob. cit., pp. 378-379.
} 
cia —ya que la expresión «objeción» se utiliza de forma genérica, pero utilizada de modo estricto solamente puede referirse a un conflicto insalvable entre la conciencia y la ley-, también al hablar de la objeción al aborto cabe decir que el personal sanitario que entiende que su conciencia no le permite intervenir en el aborto no es en verdad un objetor que se opone a cumplir la ley, «sino que es un ciudadano que ejercita su derecho a actuar conforme la ley general en lugar de acogerse a las excepciones previstas para la misma» ${ }^{82}$. La ley general sería en este caso el art. $15 \mathrm{CE}$ sobre el derecho a la vida ${ }^{83}$; las excepciones están previstas en la posterior legislación que desarrolla el texto constitucional; desde una u otra perspectiva, se ejerce la libertad de la conciencia que se opone a llevar a cabo actividades permitidas — no impuestas — por el ordenamiento jurídico. De ahí que la ley de 2010 citada, en su rigor, al limitar en exceso la posibilidad práctica de la objeción, resulte en realidad desconocedora de diversos aspectos de un derecho que los arts. 15 y $16 \mathrm{CE}$ evidentemente tutelan.

\subsubsection{Los tratamientos médicos}

La oposición a determinados tratamientos médicos es algo que posee una base fundamentalmente religiosa, si bien la complejidad del tema lo abre a diversos otros matices que la doctrina no ha dejado de señalar: «La objeción de conciencia a la práctica de ciertos tratamientos médicos implica una compleja concurrencia de aspectos jurídicos y deontológicos ${ }^{84}$. El caso se da sobre todo entre algunas confesiones que se niegan a tales tratamientos por considerarlos contrarios a su interpretación de los textos sagrados. La confesión más conocida en este campo son los Testigos de Jehová ${ }^{85}$.

Éste último es el caso de la "Christian Science», una entidad religiosa que rechaza todo sistema curativo que no sea la oración ${ }^{86}$. El segundo supuesto es el de las confesiones que consideran impuros a determinados animales y rechazan los

${ }^{82}$ M. J. Ciáurriz, «El aborto en el Derecho español», cit., pp. 131-132.

${ }^{83}$ M. J. Ciáurriz, ob. cit., especialmente el epígrafe «El artículo 15 de la Constitución y el derecho a la vida», pp. 106-108.

${ }^{84}$ L. Álvarez Prieto, «La objeción de conciencia a las transfusiones sanguíneas», en Anuario de Derecho Eclesiástico del Estado, XVI, 2000, p. 611.

85 «En la experiencia española los casos más habituales de objeción de conciencia a tratamientos médicos han sido planteados por los Testigos de Jehová que han rechazado recibir transfusiones de sangre, con base en una interpretación estricta de un pasaje evangélico contenida en el Levítico 17.10» (S. Cañamares Arribas, ob. cit., p. 120).

${ }^{86}$ «En el Derecho comparado destaca la objeción d conciencia a tratamientos médicos que plantean los miembros de la llamada Christian Science, que creen que cualquier enfermedad puede sanar a través, exclusivamente, de la oración, considerando ilícito el recurso a tratamientos médicos de forma generalizada» (S. Cañamares Arribas, ob. cit., p. 120, nota 29). 
medicamentos en cuya fórmula entran componentes que proceden de aquéllos. Y el primero, que con mucho es el más conocido - y el que ha popularizado en todo el mundo, por encima de cualquier otro ejemplo, este tipo de objeción- es el rechazo de los Testigos de Jehová a las transfusiones de sangre ${ }^{87}$. Será, pues, en este supuesto en el que fijaremos la atención como modelo de objeción de conciencia a tratamientos médicos.

La gran difusión en todo el mundo de los Testigos de Jehová, y su constante y universal rechazo a las transfusiones de sangre, han dado lugar a una amplia bibliografía, una notable legislación y una abundante jurisprudencia. En principio, se trata de un enfrentamiento entre la evitación de la muerte que los ordenamientos jurídicos pretenden ofrecer - $\mathrm{y}$ en no pocos casos imponer- al paciente, y la negativa de éste a salvar su propia vida o la de las personas situadas bajo su responsabilidad — menores de edad, incapacitados- si tal salvación sólo puede alcanzarse mediante aquel citado tratamiento. No buscan ni desean la muerte; pero no quieren conservar su vida a costa de transgredir sus deberes religiosos. Para los Testigos, la Biblia —en la lectura que hacen de sus textosprohíbe absolutamente las transfusiones, y en consecuencia no pueden aceptar la salud y evitar la muerte mediante un procedimiento rechazado por la Divinidad.

Juegan en este terreno, según los casos, cuatro voluntades: la del enfermo, la del menor o incapaz sometidos a tutela, la del médico que considera que ha de salvar la vida del enfermo por los medios que considera imprescindibles, y la del juez que ha de decidir entre la voluntad en principio negativa del enfermo y la en principio positiva del facultativo sanitario. En consecuencia, el análisis de esta problemática «no puede ceñirse a la sola perspectiva de la libertad religiosa, sino que tiene su repercusión en el derecho sobre el propio cuerpo, el derecho a la intimidad personal y familiar, el derecho-deber que corresponde a los padres en relación a la vida, la salud y la educación de sus hijos, etc.» ${ }^{88}$.

Por referirnos a la situación que durante años se ha venido dando en España, los casos concretos se han presentado así: el médico determina la imprescindible utilización de la transfusión de sangre, el enfermo la rechaza, el juez ordena practicarla, y el médico tiene o bien que obedecer al juez o bien que atenerse a la negativa del enfermo. Cabe suponer delito en la decisión del Testigo de Jehová cuando desobedece al juez; cabe en el médico en igual supuesto, si no sigue la orden judicial; cabe en el juez si aplica negligentemente la ley. Y, sobre todo, ha de determinarse legal o jurisprudencialmente - lo que en cierto modo debe resolver en uno u otro sentido el conflicto - si forma o no parte del contenido de la libertad religiosa la opción por la muerte en el supuesto del rechace, por motivos de conciencia, de algún o algunos tipos de tratamientos médicos.

${ }^{87}$ Vid. L. Prieto Sanchis, ob. cit., pp. 89-92.

${ }^{88}$ L. Álvarez Prieto, ob. cit., p. 611. 
En España el tema no ha sido afrontado muy especialmente por la jurisprudencia. Una breve referencia a la misma muestra que la doctrina jurisprudencial ha experimentado una cierta evolución, tanto en torno a la objeción del adulto que rechaza la transfusión para sí mismo como a la referida al menor en cuyo nombre actúa quien detenta la patria potestad.

La tendencia inicial fue, por parte del TS, la de proteger el derecho a la vida frente a la opción religiosa, al amparar en 1978 la decisión del juez que había ordenado una transfusión y que se vió denunciado por los padres de la menor que rechazaban tal tratamiento; una decisión a cuyo tenor el juez no solamente podría sino que debería autorizar la administración forzosa de la transfusión si ello es necesario para salvar la vida o la salud de un menor; línea doctrinal que fue confirmada en otras sentencias de años inmediatos ${ }^{89}$. Y, seguidamente, ratificó la misma el TC en sentencia de 20 de junio de 1984: «Existe una autorización legítima derivada de los artículos 3 y 5 de la Ley de libertad religiosa para la actuación judicial, ya que el derecho de libertad religiosa garantizado por el art. 16.1 de la Constitución tiene como límite la salud de las personas, y en uso de ella actuó el magistrado juez» ${ }^{90}$.

Como se ha indicado ya más de una vez, la tendencia jurisprudencial en el campo de la objeción se ha ido modificando con posterioridad, y eso mismo ha sucedido también en lo que se refiere a los tratamientos médicos. De hecho, se tendió a liberar a los jueces de la obligación de imponer los tratamientos objetados, al menos declarando que si el juez no impone el tratamiento ello no supone que cometa un delito ${ }^{91}$. Así lo pasó a entender el TC a partir de 1990 y la nueva línea jurisprudencial se fue sucesivamente abriendo camino, pudiendo citarse por todas la decisión del Tribunal Superior de Justicia de Madrid del 23 de diciembre de 1992 que rechaza la tesis de que el juez tenga necesariamente que autorizar la transfusión de sangre para no incurrir en un delito de omisión del deber de socorro previsto en el Código penal ${ }^{92}$.

Fundamental en esta línea es la conocida sentencia 154/2002, de 18 de julio, del TC, que viene siendo considerada paradigmática por toda la doctrina y constituye el texto jurisprudencial con mayor influencia y presencia en la bibliografía ${ }^{93}$. El caso cobró relieve también por las singulares circunstancias que lo

${ }^{89}$ Vid. al respecto M. Cebriá, Objeciones de conciencia a intervenciones médicas. Doctrina y Jurisprudencia, Thomson-Aranzadi, Cizur Menor 2005, passim.

${ }^{90}$ Vid. en R. Navarro-Valls, J. Martínez-Torrón, M.A. Jusdado, «La objeción de conciencia a tratamientos médicos», en VV.AA., Las relaciones entre la Iglesia y el Estado. Estudios en memoria del Prof. Pedro Lombardía, Editoriales de Derecho Reunidas, Madrid 1989, pp. 950-954.

${ }^{91}$ Vid. J. M. González del Valle, ob. cit., p. 310.

${ }^{92}$ Vid. R. Navarro-Valls, J. Martínez-Torrón, Conflictos entre Conciencia y Ley, cit., p. 202.

${ }^{93}$ Vid. en Anuario de Derecho Eclesiástico del Estado, XIX, 2003, pp. 491-519. Sobre la misma vid. L. Álvarez Prieto, ob. cit., pp. 611 ss. 
envolvieron. Su protagonista es un chico de trece años residente en un pueblo de la provincia de Huesca, hijo de padres Testigos de Jehová y seguidor él mismo de esta religión. Tuvo una caída de bicicleta a consecuencia de la cual empezó a padecer fuertes hemorragias, tanto que los médicos consideraron imprescindible realizarle una transfusión de sangre. El enfermo hubo de pasar por diferentes centros sanitarios y el proceso de su enfermedad resultó prolongado y complejo. Lo esencial es señalar que, rechazada la transfusión por los padres, fue solicitada por los médicos una autorización judicial que se les concedió y que los padres acataron. Fue entonces el menor quien se negó a la transfusión, con tal convicción y empeño que los médicos temieron males mayores y suspendieron la actuación. En vez de imponerle ésta al menor reluctante, rogaron la intervención convincente de los padres ante su hijo, y a ésta ellos se negaron a su vez, entendiendo que una cosa era resignarse a la disposición del juez y otra actuar ellos mismos para convencer a su hijo de algo contrario a lo que le habían enseñado al educarle. El regreso del niño desde la clínica al domicilio familiar, un nuevo requerimiento médico al juez para que ordenase la transfusión ante la ya extrema gravedad del enfermo, una nueva orden judicial que los padres volvieron a acatar, un nuevo traslado a un hospital..., todo fue ya inútil y el enfermó falleció.

Se acusó a los padres de responsabilidad penal por este fallecimiento, atribuyéndoles un delito de homicidio por omisión, resultando absueltos en 1996 por la Audiencia Provincial de Huesca ${ }^{94}$; no se consideró exigible ni la renuncia de los padres a sus convicciones religiosas ni que debiesen conducir a su hijo hacia unas ideas contrarias a las que le habían transmitido durante los años de su educación. Así pues, la libertad religiosa toma entonces el protagonismo que se le negara durante años de decisiones jurisprudenciales anteriores. El TS anuló esta sentencia en $1997^{95}$ y condenó a los padres por homicidio, delito acompañado por una muy cualificada atenuante de estado pasional. Y, en fin, vino a resolver el caso el TC con la ya citada 154/2002, capital en este terreno, que absuelve definitivamente a los padres en base a que: a) a sus trece años, el menor poseía ya una madurez bastante para poder ejercitar su derecho de libertad religiosa, y b) de la libertad religiosa de los propios padres se derivaba también su derecho a defender sus convicciones religiosas, al menos hasta el grado de no verse obligados a tratar de llevar a su hijo hacia una conducta contraria a las enseñanzas éticas que legítimamente le habían transmitido a lo largo de toda su vida.

No declara el TC que el derecho a la vida no resulte ser un valor prevalente; tratando de evitar asimismo la clásica confrontación vida-conciencia, que no es

\footnotetext{
${ }^{94}$ Sentencia de la Audiencia Provincial de Huesca n ${ }^{\circ}$ 196. de 20 de noviembre de 1996; vid. L. Álvarez Prieto, ob. cit., pp. 614-615.

${ }^{95}$ Sentencia del TS de 27 de junio de 1997. Vid. al respecto L. Álvárez Prieto, ob. cit., pp. 612 y $615-616$.
} 
otra que la referida al iniciar estas páginas entre ley y conciencia, ya que la vida se considera un valor de todo punto superior que el Derecho ha de tutelar, y ya que la garantía de la libertad religiosa tiene el límite del orden público protegido por la ley (art. 16.1. CE). La vía intermedia elegida por el Alto Tribunal supone reconocer que el derecho a la vida del menor es prevalente hasta poder exigirse a los padres que permitan su tutela por el poder público incluso en contra de sus creencias religiosas, pero no hasta el punto de obligarles a tratar de imponer al menor su voluntad contraria a las creencias en las que ellos mismos le habían educado ${ }^{96}$. Con lo que - y esto ha de subrayarse- fue la negativa del menor la que prevaleció, contra las órdenes de los jueces, la decisión de los médicos y la aceptación de éstas por los padres; la libertad religiosa es un derecho fundamental de la persona humana — venimos a concluir- que poseen no solamente los adultos sino todas las personas, y ello les autoriza para decidir cuál será su conducta en los conflictos ley-conciencia, dentro de unas circunstancias en las que su opción de conciencia esté clara y pueda considerársela atendible por el Derecho. Así ha llegado a establecerse como generalmente aceptada la tesis de que, ante el conflicto entre un mandato general y un derecho fundamental, «el interés se centra en la búsqueda del necesario equilibrio entre ambos o en hallar la regla que nos permita identificar qué es lo que ha de prevalecer en cada caso. Dicho de otro modo, se trata de ponderar los intereses que entran en conflicto... Cuando el ejercicio de un derecho queda obstaculizado por la aplicación de su límite no significa que éste desplace o excepcione a aquél. Ambos elementos continúan siendo relevantes porque estamos ante un régimen de concurrencia normativa y no de exclusión. Por ello la ponderación de los intereses en conflicto adquirirá connotaciones diferentes en cada caso concreto, sin que sea fácil elaborar una suerte de teoría general sobre su resolución ${ }^{97}$.

\subsubsection{El consentimiento informado}

En relación con todo lo antedicho, se plantea hoy como transcendental en este campo el cambio de criterio que se ha ido operando en torno al dato de a quien corresponde la última decisión en relación con los tratamientos médicos aconsejados por la ciencia sanitaria. Durante muchísimo tiempo, ello ha sido competencia exclusiva del personal médico; desde hace algunos años, se ha producido una progresiva afirmación de la autonomía del paciente. «La privación de información al paciente era un práctica que quedaba al arbitrio del médico

${ }^{96}$ Sobre la normativa y jurisprudencia acerca de los derechos del menor en estos terrenos, vid. A. González-Varas, Derecho y conciencia, cit., epígrafe «El consentimiento del menor en los tratamientos médicos en España», pp. 231-237.

${ }^{97}$ A. González-Varas, ob. cit., pp. 44-45. 
cuando predominaba la tradicional relación paternalista entre él y el paciente, en el momento presente se trata de un comportamiento reservado a casos extremos» ${ }^{98}$; pero hoy predomina la tesis del «consentimiento informado», es decir, «la afirmación que ha de pronunciar el paciente, previa información del médico sobre su estado, para que sea legítima la aplicación de un tratamiento médico, así como su sustitución por otro e, incluso, la omisión de una terapia» ${ }^{99}$. El consentimiento informado constituye, en efecto, «el reflejo más cualificado del cambio operado en la relación médico-enfermo y, muy especialmente, en los principios que rigen la ética médica» ${ }^{100}$.

A tal efecto, una nueva ley — la 41/2002, de 14 de noviembre ${ }^{101}$, reguladora de la autonomía del paciente ${ }^{102}$ — ha venido a establecer en España una nueva normativa que determina la necesidad del consentimiento informado, y cuanto al mismo y a sus excepciones se refiere. Sin necesidad de información al paciente acerca del tratamiento que se le quiere aplicar, y sin intervención judicial previa, tendente a determinar, de ser necesario, el grado de autonomía del enfermo en cada caso concreto en relación con el tratamiento sanitario que se le prescribe, los médicos solamente podrán actuar según sus propios criterios en circunstancias absolutamente singulares que la ley de modo expreso determina. No es que la ley se plantee el tema de la objeción, sino que atiende específicamente a la autonomía de la voluntad del paciente, a su derecho a recibir un tratamiento médico solamente después de haber dado su consentimiento informado ${ }^{103}$. Y es que, en efecto, en esta nueva modalidad en la relación enfermo-médico, y al ser «el principio de autonomía del paciente el que concilie la libertad de conciencia del enfermo y la ética médica», el enfermo pasa a ser «el protagonista principal y se le reconoce la capacidad para tomar decisiones, a ser informado sobre las diversas alternativas del tratamiento y a conocer la opinión del médico» ${ }^{104}$; en resumen, como se ha indicado, a que su consentimiento sea el resultado de su conocimiento: el consentimiento informado, que nace del juego en común de la información recibida y de su personal derecho a la libertad.

98 A. González-Varas, ob. cit., p. 117.

${ }^{99}$ A. González-Varas, ob. cit., p. 116.

${ }^{100}$ J. A. Souto Paz, ob. cit., p. 278.

${ }^{101}$ Vid. J. A. Souto Paz, ob. cit., p. 281.

${ }^{102}$ Ley 41/2002, de 14 de noviembre. Reguladora de la autonomía del paciente y de derechos y obligaciones en materia de información y documentación clínica (vid. al respecto M. J. Villa Robledo, M. Rodríguez Blanco, «Legislación del Estado Español», en Anuario de Derecho Eclesiástico del Estado, XIX, 2003, pp. 409-410.

${ }^{103}$ Vid. M. Cebriá García, ob. cit., pp. 32 ss.

${ }^{104}$ M. González Sánchez, «La objeción de conciencia del personal sanitario a las instrucciones previas por motivos religiosos», en I. Martín Sánchez, M. González Sánchez, Algunas cuestiones controvertidas, cit., p. 283. 
La citada Ley de 2002 sobre la autonomía del enfermo, como ya hemos indicado, muy excepcionalmente permite que se lleven a cabo tratamientos médicos sin contar con el consentimiento del paciente; en su art. 9.2 señala al efecto tan sólo dos supuestos ${ }^{105}$ : el «riesgo para la salud pública a causa de razones sanitarias establecidas por la ley» —es la hipótesis de epidemias y situaciones similares - y los casos en que «existe riesgo inmediato grave para la integridad física o psíquica del enfermo y no es posible conseguir su autorización». La doctrina duda sobre la más correcta interpretación de estas últimas palabras: «no es posible...» puede significar tanto que no se puede convencer al enfermo de que otorgue su asentimiento, cuanto que está imposibilitado física o psíquicamente para otorgarlo. Solamente en este segundo sentido tendría lógica la excepción y por tanto la intervención no autorizada expresamente; si el médico pudiese llevar esta a cabo, invocando tal excepción, cuando no es posible obtener e consentimiento porque el enfermo capaz se niega a darlo, se vendría abajo todo el tema de la objeción de conciencia de los Testigos de Jehová, incluso en el grado en que la misma goza del apoyo jurisprudencial ya conocido, y lo mismo cabría decir de otros supuestos similares.

\subsubsection{Las instrucciones previas o testamentos vitales}

Debe aún decirse una palabra sobre las llamadas instrucciones previas o testamentos vitales. Tales instrucciones son un derivado del consentimiento informado, redactadas con anticipación a sus posibles enfermedades, en las que las personas dejan expresada fehacientemente su voluntad, sus instrucciones al médico, para el caso de no poder expresarlas en el momento en que se hace precisa la intervención del mismo ${ }^{106}$.

«La legislación española también admite que una persona mayor de edad, capaz y libre, manifieste su voluntad anticipadamente y por escrito, con el objeto de que ésta se cumpla» ${ }^{107}$ en lo casos previstos por la normativa, en este caso por la Ley 41/2002, art. 11.1, según la cual «Por el documento de instrucciones previas, una persona mayor de edad, capaz y libre, manifiesta anticipadamente su voluntad, con objeto de que ésta se cumpla en el momento en que llegue a situaciones en cuyas circunstancias no sea capaz de expresarlos personalmente, sobre los cuidados y el tratamiento de su salud o, una vez llegado el fallecimiento, sobre el destino de su cuerpo o de los órganos del mismo» ${ }^{108}$. Por supuesto, los

${ }^{105}$ R. Navarro-Valls, J. Martínez-Torrón, ob. cit., p. 214.

${ }^{106}$ Vid. M. J. Ciáurriz, «La Declaración Universal de Bioética y el pluralismo religioso», cit., pp. 116-117.

${ }^{107}$ A. González-Varas, ob. cit., p. 131.

${ }^{108}$ Vid. en M. González Sánchez, ob. cit., p. 284. 
motivos inspiradores de tales instrucciones pueden ser de muy diferentes tipos; nos interesa subrayar tan sólo que puede tratarse de motivos de conciencia, de objeciones de conciencia, que habrán de respetarse, a determinadas intervenciones médicas.

\subsubsection{La reproducción asistida}

El moderno desarrollo de la biología permite hoy la utilización de técnicas relacionadas con la vida humana que eran impensables hace pocos años, y que ignoramos hasta dónde podrán llegar. En este contexto se enmarcan las nuevas técnicas de reproducción asistida, las cuáles, como toda esta temática, tocan por lo común muy directamente a la conciencia, tanto cuando la misma se basa en creencias religiosas como lo hace en otros tipos de convicciones determinantes de la conducta humana ${ }^{109}$. De ahí el protagonismo que están cobrando en este terreno la Bioética y el Bioderecho: la calificación ética de las nuevas vías de la manipulación y experimentación genética y su correspondiente regulación jurídica. Como ha apuntado la doctrina, las objeciones de conciencia abarcan hasta las investigaciones científicas que, a partir de ensayos de laboratorio y experimentos con animales, invaden ya con habitualidad el espacio de la propia vida del ser humano $^{110}$.

En este contexto, y en cuanto que hoy es posible llegar a la reproducción humana por muy varias vías diferentes de la tradicional forma de unión sexual, las Confesiones religiosas se han visto en la necesidad de pronunciarse de algún modo al respecto, a efectos de sentar criterios o proporcionar orientaciones a sus miembros, tal como también lo hacen en relación con el aborto y la eutanasia, si bien estas dos realidades sean tan antiguas — si no en sus modalidades, al menos en su esencia - tanto como la propia vida humana sobre la tierra ${ }^{111}$. Y, por supuesto, no solamente los criterios religiosos inspirarán las actitudes de conciencia ante tales fenómenos, y en concreto ante la reproducción asistida.

En nuestro ordenamiento, se han sucedido al respecto una serie de leyes relativas tanto a las técnicas reproductivas como a la utilización de embriones y fetos humanos; la más reciente es la Ley 14/2006 sobre técnicas de reproducción

${ }^{109}$ Una extensa referencia a todos los problemas que afectan a la procreación, en relación con la libertad personal de decisión, en J. Robert, Jean Duffar, Droits de l'homme et libertés fondamentales, Montchestien, París 1999, pp. 225 ss.

${ }^{110}$ A. González-Varas, ob. cit., pp. 93-94.

${ }^{111}$ Vid. M. J. Ciáurriz, «La Declaración Universal...», cit., p. 90, acerca de la enseñanza del Islam sobre la reproducción asistida; p. 94 sobre el Judaísmo; p. 99 sobre las Confesiones evangélicas; p. 108 sobre la Iglesia católica. 
humana asistida ${ }^{112}$, que ha ido además acompañada por diferentes pronunciamientos jurisprudenciales. En este campo se han presentado como temas a discutir, sometidos a posibles objeciones de conciencia tanto del personal sanitario como de las personas directamente afectadas por las nuevas prácticas, tanto la inseminación artificial como la fecundación in vitro, la transferencia de embriones y otras prácticas semejantes.

En todo caso, la Ley de 2006 no hace referencia alguna a la objeción de conciencia, sino que fija normas sobre las técnicas mencionadas; es de desear que la todavía insegura jurisprudencia vaya sentando criterios sólidos al respecto.

\subsubsection{La eutanasia}

La eutanasia, u opción voluntaria por la muerte, en casos de enfermedad extrema, sufrimientos difíciles de soportar, prolongación artificial de la vida, y situaciones similares, es un problema que ha cobrado notable importancia en muchos países en los tiempos más recientes ${ }^{113}$. No se trata de un suicidio - privarse personal y voluntariamente de la vida por cualquier causa - sino, según el diccionario, de la «muerte sin sufrimiento físico, especialmente la provocada voluntariamente a quien, padeciendo una enfermedad incurable, la solicita para poner fin a sus sufrimientos» ${ }^{114}$.

En líneas generales, se trata de un delito, y desde luego se oponen a la misma todas las confesiones religiosas ${ }^{115}$, las cuáles parten de que la vida es un don divino de la que el hombre no puede disponer; para la mayoría de las mismas, la aceptación del sufrimiento que normalmente acompaña a la enfermedad y la muerte es una muestra de aceptación de la voluntad de Dios y posee un sentido purificador ${ }^{116}$. Para las Confesiones, la eutanasia, en principio, resulta «un acto condenable que degrada el valor de la vida humana y que abre las puertas a situaciones aberrantes al poner en manos de los médicos, los pacientes, las familias e incluso la Administración pública una función que de ninguna manera les co-

${ }^{112}$ Vid. al respecto M. J. Villa Robledo, M. Rodríguez Blanco, «Legislación del Estado Español», en Anuario de derecho Eclesiástico del Estado, XXIII, 2007, pp. 471-472.

${ }^{113} \mathrm{Vid}$. al respecto las varias aportaciones de diversos autores que se contienen en la obra de I. Martín Sánchez (coord.), Bioética, Religión y Salud, Comunidad de Madrid, Madrid 2005.

${ }^{114}$ El pequeño ESPASA, Espasa-Calpe, Madrid 1988, p. 530.

${ }^{115}$ Las Confesiones mantienen esquemas muy similares en gran parte de los temas referentes a la conservación de la vida humana (vid. I. C. Ibán, «Confesiones religiosas», en I. C. Ibán, L. Prieto, A. Motilla, ob. cit., pp. 167-168).

${ }^{116}$ M. J. Ciáurriz, «La Declaración Universal...», cit., pp. 92-93, en relación con las enseñanzas del Islam sobre la eutanasia; p. 97, en relación con el Judaísmo; pp. 102-103, en relación con las Confesiones evangélicas; pp. 114-117, en relación con la Iglesia católica. 
rresponde» ${ }^{117}$. Ello motiva que, en buena medida, las objeciones de conciencia a la eutanasia, por parte de quienes se niegan a colaborar en la misma, tenga en la mayoría de los casos un sentido religioso; pero también cabe, y se da de hecho, la oposición por motivos de conciencia no necesariamente procedentes de la religión. Y, como decimos, buena parte de las legislaciones civiles la consideran, al menos en sus formas extremas, un delito.

Debe tenerse también en cuenta que la eutanasia no es reducible a un concepto único; distinta es la activa o directa, que busca directamente la muerte del enfermo, que la pasiva o indirecta, que trata de paliar el dolor mediante un tratamiento que puede como efecto no buscado acortar la vida, o bien que trata de no prolongar artificialmente la vida mediante la aplicación de remedios extremos que alargan también el sufrimiento, y que de no aplicarse se produciría el fallecimiento $^{118}$. Todas las religiones presentes en España matizan en consecuencia y de algún modo su rechazo, y lo mismo hacen también muchos ordenamientos estatales.

En España, en concreto, el Código Penal tipifica como delito la eutanasia $^{119}$, al establecer en su art. 143 diferentes penas para quien induzca a otro al suicidio o coopere en la realización de éste, penas que aumentan en grado si de tal cooperación se sigue efectivamente la muerte, y que en cambio son de menor gravedad referidas a el que causare o cooperare activamente con actos necesarios y directos a la muerte de otro, por la petición expresa, seria e inequívoca de éste, en el caso de que la víctima sufriera una enfermedad grave que conduciría necesariamente a su muerte, o que produjera graves padecimientos permanentes y difíciles de soportar».

La normativa española, pues, no alude en este caso a la objeción de conciencia, pero en tanto considera delito la eutanasia han de protegerse las negativas a cooperar con la voluntad del enfermo o de la familia que pretende infringir la muerte mediante eutanasia directa. Y, en efecto, en la antes citada Ley de 2002 sobre la autonomía del paciente y las instrucciones previas, ya se establece en su art. 11 que estas instrucciones no serán aplicadas cuando sean «contrarias al ordenamiento jurídico». En todo caso, algunas Comunidades Autónomas sí que han legislado al respecto y reconocido frente a la eutanasia los derechos de la objeción de conciencia ${ }^{120}$.

${ }^{117}$ M. J. Ciáurriz, ob. cit., p. 102.

${ }^{118}$ Hacen referencia a diversas clasificaciones de la eutanasia J. Robert, J. Duffar, ob. cit., pp. 220-225.

${ }^{119}$ Vid. M. J. Parejo, «Consideraciones acerca de la eutanasia: la disponibilidad de la propia vida», en Il Diritto Ecclesiastico, 116, 2005, pp. 675 ss.

${ }^{120}$ Mencionan estas regulaciones R. Navarro-Valls, J. Martínez-Torrón, ob. cit., pp. 166-169. 


\subsubsection{La objeción de conciencia farmacéutica}

Conocido es el supuesto de la posible negativa de los farmacéuticos a expender productos destinados a hacer imposible ya sea la concepción ya el posterior desarrollo del óvulo una vez fecundado, y otros medicamentos relacionados con toda esta temática ${ }^{121}$. Y no hay duda de que tal negativa puede obedecer, y normalmente obedecerá, a motivos de conciencia ${ }^{122}$.

El «Código de Ética farmacéutica y Deontología de la profesión farmacéutica», aprobado el 14 de diciembre de 2001 por la Asamblea General de Colegios Oficiales de los Farmacéuticos de España ${ }^{123}$, prevé de modo expreso la objeción de conciencia de estos profesionales frente a cualquier actuación que suponga poner sus conocimientos y su profesión al servicio de aquello que se opone a sus convicciones. El caso más frecuente y conocido, aunque no el único, es la venta de píldoras anticonceptivas ${ }^{124}$. El amparo del Colegio Oficial de Farmacéuticos a las opciones de conciencia de estos profesionales se ve apoyado por algunas sentencias que han comenzado ya a pronunciarse, tales como una del Tribunal Supremo que tuteló, en el año 2005, la objeción de conciencia farmacéutica frente a posibles sanciones derivadas de la negativa a la venta de la píldora mencionada, y otra en el mismo sentido del Tribunal Superior de Justicia de Andalucía, del año $2007^{125}$. Y también se ha iniciado la protección del mismo derecho de objeción por vía legislativa, como es el caso de la Ley 5/1999, de ordenación farmacéutica en Galicia, que toma en cuenta esta objeción: «la administración sanitaria garantizará que el derecho a la objeción de conciencia del profesional farmacéutico no limite o condicione el derecho a la salud de los ciudadanos»; en igual sentido otras leyes de 1998 (La Rioja) y 2005 (Castilla-La Mancha) ${ }^{126}$. Todas ellas tratan de armonizar dos derechos: el del ciudadano que desea recurrir al uso de determinados productos legalmente autorizados pero de destino contrario a las convicciones éticas del farmacéutico, y el de éste a negarse a dispensarlos por motivos de conciencia. En todos los casos, la administración pública tomará medidas

${ }^{121}$ Vid. el epígrafe «La prescripción y expedición forzosa de medicamentos», en A. GonzálezVaras, ob. cit., pp. 226-227.

${ }^{122}$ Vid. M. R. León Benítez, M. M. Leal Adorna, ob. cit., pp. 227-228.

${ }^{123}$ Vid. en Cuadernos de Bioética, 63, 2007, pp. 249-253.

${ }^{124}$ Incluso la doctrina se acerca al tema sobre la base de referirse a la «denominada objeción farmacéutica, consistente en la negativa a la venta de medios anticonceptivos...» (M. R. León Benitez, M. M. Leal Adorna, ob. cit., p. 227).

${ }^{125}$ Sentencias del TS de 23 de abril de 2005 y del Tribunal Superior de Justicia de Andalucía de 8 de enero de 2007.

${ }^{126}$ Vid. al respecto de toda esta temática A. González-Varas, «La objeción de conciencia del farmacéutico en la jurisprudencia y su regulación legal en España», en Revista General d Derecho Canónico y de Derecho Eclesiástico del Estado, 15, 2007, passim. 
para respetar ambos derechos, siendo por lo común la más normal la de asegurar la disponibilidad del producto en otros establecimientos del mismo tipo cuyos titulares no tengan inconveniente en su distribución.

Se trata de un tema que puede alcanzar un mayor desarrollo futuro, si se pretendiera obligar a los profesionales de la farmacia a obrar en contra de sus personales convicciones éticas.

\subsection{Las objeciones de conciencia en el ámbito público}

Si las objeciones que hemos visto en relación con la biología, la salud y la reproducción, mantenimiento y extinción de la vida, poseen —amén de su indudable repercusión fuera del ámbito personal- una dimensión fundamentalmente privada, existen otros modelos de objeciones que — pese a su indudable dimensión relacionada con la persona- afectan fundamentalmente a la actuación de ésta en la vida pública ${ }^{127}$. Es de éstas de las que pasaremos a ocuparnos en los apartados subsiguientes, recogiendo los más importantes supuestos que señala la doctrina: las objeciones en el terreno fiscal y en el del juramento para el desempeño de cargos públicos, en el campo laboral, en el de la participación en jurados, simbología religiosa, y finalmente en relación con los temas educativos; una enumeración que por otro lado tampoco resulta exhaustiva ${ }^{128}$, pues, como se ha dicho alguna vez, «la posibilidad de plantear objeciones de conciencia es infinita» ${ }^{129}$.

\subsubsection{La objeción fiscal}

Muy brevemente, ha de recordarse una concreta objeción de conciencia que se encuentra en directa relación con las objeciones al servicio militar y al aborto, e incluso puede catalogarse como un caso de incumplimiento de deberes civi$\operatorname{les}^{130}$. Se trata de quien, por motivos de conciencia, no solamente rechaza aquel servicio o la realización de abortos, sino que rechaza el cumplimiento de las obligaciones tributarias en el porcentaje correspondiente a los gastos militares o a las

${ }^{127}$ Hoy, como ha escrito S. Berlingò («La condizione delle Chiese in Europa», en Il Diritto Ecclesiastico, CXIII, 4, Giuffrè, Milano 2002, p. 1313), «le religioni e, in genere, il religioso e il sacro ... sono chiamati alla ribalta in un ruolo dal rilievo non trascurabile. Si tratta di spendersi non solo nella nicchia della sfera più intima dell'esistenza, eletta a refugio di ogni moto pulsionale e immaginifico, refractario a qualsiasi tentativo di "omogeneizzazioine modernizzante", ma altresì nella sfera pubblica e societaria».

${ }^{128}$ Vid. M. J. Ciáurriz, «Objeción de conciencia y Estado democrático», cit., p. 49.

${ }^{129}$ J. M. González del Valle, ob. cit., p.314.

${ }^{130}$ Vid. L. Prieto Sanchis, ob. cit., p. 86. 
subvenciones al aborto efectuadas con cargo al erario público; sin tener que limitarse el concepto a estos ejemplos, ya que el supuesto de objeción se referirá a los casos, sean los que sean, en que «se pretende eludir el pago de aquellos impuestos del Estado que se destinan a actividades contrarias a las conciencias de los contribuyentes que la aducen» ${ }^{131}$.

El tema ha sido tocado a nivel internacional en relación con «el cumplimiento del Pacto Internacional de Derechos Civiles y Políticos» y «existen en España una serie de sentencias en las que se analizan casos de objeción de conciencia fiscal» ${ }^{132}$, sentencias que la doctrina no ha dejado lógicamente de recoger ${ }^{133}$.

Dos puntos pueden resaltarse para completar la referencia a este modelo de posible objeción. El primero, que el verdadero objetor, no quien simplemente trata de eludir impuestos, no pretende pagar menos, sino que el destino de sus pagos no llegue a recaer en los hechos que rechaza; el segundo, que se trata de una objeción que, al incidir directamente sobre el delicado tema de la política económica, es vista con todo recelo por el Estado, que trata de minimizarla reduciéndola a mera «desobediencia civil» ${ }^{134}$ o figuras similares, lejos del concepto ético de objeción. Sin embargo, cabe sin duda la defensa doctrinal de quien extiende, por ejemplo, su oposición al aborto a la realización del mismo mediante su personal contribución económica. Respetado el derecho del personal sanitario a no practicar abortos, sería coherente con los valores de libertad y justicia que han de inspirar todo el ordenamiento jurídico español (art. 1 CE) el buscar fórmulas que tutelen la objeción a la llamada cooperación indirecta, cooperación que el objetor fiscal trata de evitar.

\subsubsection{Objeción de conciencia y relaciones laborales}

La doctrina ha puesto de relieve la cuestión que late en el ámbito de las relaciones laborales, en cuanto pudiera objetarse por razones de conciencia al cumplimiento de las obligaciones derivadas de las mismas: «este género de obligaciones de base contractual son libremente asumidas y, por ello mismo, parecen

${ }^{131}$ M. R. León Benítez, M. M. Leal Adorna, ob. cit., p. 234.

${ }^{132}$ J. M. González del Valle, ob. cit., p. 306.

${ }^{133}$ J. M. González del Valle, ob. cit., pp. 307-309.

${ }^{134} \mathrm{La}$ «objeción fiscal constituye un caso de desobediencia indirecta al Derecho, muy cercano a lo que se conoce con el nombre de desobediencia civil» (L. Prieto Sanchis, ob. cit., p. 86). Vid. también al respecto, insistiendo en la distinción entre objeción de conciencia y desobediencia civil, J. G. Navarro Floria, El derecho a la objeción de conciencia, Editorial Ábaco de Rodolfo Depalma, Buenos Aires 2004, pp. 32-34. La doctrina del Consejo de Estado sobre el tema, en G. Codes Belda, El Derecho Eclesiástico en la doctrina del Consejo de Estado, Universidad de Córdoba, 2005, especialmente el epígrafe «Objeción de conciencia versus desobediencia civil», pp. 146-148. 
revestir mayor fuerza que los deberes impuestos por el Estado... No parecería lógico que un individuo se vincule al cumplimiento de una actividad que pugna con su dictamen de conciencia. En definitiva, la actitud de obediencia al Derecho parece que ha de ser más vigorosa cuando tiene por objeto obligaciones libremente asumidas que cuando se trata de deberes impuestos directamente por la ley» ${ }^{135}$.

En todo caso, y tenida en cuenta esta observación, no dejan de presentarse casos de posibles conflictos relacionados con la «colisión entre los principios religiosos o morales del trabajador y su obligación de desarrollar una determinada actividad. Normalmente esta obligación se encuentra contractualmente definida, de manera que el conflicto entre conciencia y ley no se produce de manera directa, sino sólo indirecta, en la medida en que el contrato está respaldado por la legislación. No ha de olvidarse, en todo caso, que la contratación laboral, aún siendo en rigor una relación de derecho privado, se halla sometida a una normativa que presenta algunas de las características del derecho público, por el acentuado interés social que tiene esa clase de contratos. Lo cual determina que en el mundo de las relaciones de trabajo la voluntad de las partes sea menos autónoma y esté sometida a determinados condicionantes que serían poco concebibles en la dinámica contractual ordinaria» ${ }^{136}$. Entre estos casos de posibles colisiones, pueden recordarse la negativa a trabajar en días que la propia religión considera no laborables, o el propósito de utilizar durante el trabajo una vestimenta no aceptada por la empresa.

El caso del descanso festivo es sin duda el más relevante y frecuente, y se da a partir del dato de que el descanso laboral suele estar establecido los domingos, mientras p.e. los judíos lo llevan al sábado, otro tanto los adventistas, los musulmanes al viernes, todo ello con matices que hacen de difícil solución esta temática, a la que hay que añadir la existencia en cada Confesión de fiestas religiosas propias a lo largo del año ${ }^{137}$.

En cuanto se refiere a España, inciden en el tema el Estatuto de los Trabajadores, la Ley de Libertad Religiosa y los Acuerdos del Estado con las Confesiones religiosas. La citada Ley es muy poco concreta al respeto, al establecer tan sólo un derecho genérico de toda persona a conmemorar sus festividades (art. 21.) como uno de los derechos en que se desarrolla la libertad religiosa personal. El Estatuto señala el domingo como el día de descanso semanal, pero cabe por convenio colectivo o contrato de trabajo regular de otra manera el tema (art. 37.1), estableciéndose además la prohibición de pactos individuales, así como de decisiones unilaterales por parte de la empresa, que discriminen a algunos trabajadores por causas religiosas en relación con el salario y las jornadas de trabajo ${ }^{138}$.

\footnotetext{
${ }^{135}$ L. Prieto Sanchis, ob. cit., pp. 86-87.

${ }^{136}$ R. Navarro-Valls, J. Martínez-Torrón, ob. cit., p. 396.

${ }^{137}$ Vid. M. R. León Benítez, M. M. Leal Adorna, ob. cit., p. 231.

${ }^{138}$ Vid. G. Escobar Roca, ob. cit., pp. 370 ss.
} 
En aplicación de tal normativa, el ordenamiento jurídico español y muy en especial nuestra jurisprudencia, a partir de una sentencia del TC 19/1985 de 13 de febrero ${ }^{139}$, se ha inclinado determinadamente a favor del empresario en lo que hace al descanso semanal de los trabajadores pertenecientes a confesiones que señalan al efecto días distintos del domingo. Por lo común, o se ha negado el derecho del trabajador a descansar otro día si la empresa no se lo permite o, si de algún modo se toma en cuenta la excepción a favor de quienes pertenezcan a determinados credos, es para hacer referencia a la posibilidad de un acuerdo entre el empleado y el empresario, en el que en realidad éste no posee obligación alguna al respecto. La primera es la actitud jurisprudencial mayoritaria; la segunda es la solución adoptada por los Acuerdos de 1992 por el Estado español con evangélicos musulmanes y judíos ${ }^{140}$.

En los respectivos artículos 12 de los tres Acuerdos ${ }^{141}$, se señala que se podrá fijar un día específico semanal de descanso, distinto del domingo, para los fieles de las Confesiones interesadas, «siempre que medie acuerdo entra las partes», «previo acuerdo entre las partes». Al no fijársele a la parte empresarial condición alguna en orden al mencionado acuerdo con la parte trabajadora, es obvio que se trata de una declaración de buenas intenciones cuya efectividad no se inclina del lado del objetor de conciencia ${ }^{142}$. Y, asimismo, se menciona en los citados artículos 12 una relación concreta de festividades anuales judías e islámicas, que pueden sustituir a otras fijadas por el calendario laboral, indicándose también que así será siempre que medie acuerdo entre las partes, o a petición de los interesados, sin fijar obligación alguna para la empresa más allá de esta declaración abstracta.

\subsubsection{El juramento}

Frente a la tradicional praxis de prestar juramento como prueba del compromiso que se adquiere al asumir un cargo o función públicos, surgieron en momentos ya no tan recientes diferentes objeciones de conciencia, provenientes bien de convicciones laicas que no permiten jurar —es decir, adquirir un com-

${ }^{139}$ Vid. al respecto J.A. Souto Paz, «Jurisprudencia del Tribunal Constitucional», en Anuario de Derecho Eclesiástico del Estado, II, 1986, pp. 518-520.

${ }^{140}$ Vid. A. Castro Jover, «Libertad religiosa y descanso semanal», en Anuario de Derecho Eclesiástico del Estado, VI, 1990, pp. 299 ss.; R. Rodríguez Chacón, El factor religioso, cit., pp. 85-93.

${ }^{141}$ Vid. los respectivos artículos 12 de estos Acuerdos en J. Fornés, M. Blanco, B. Castillo, F. Pérez-Madrid, Legislación eclesiástica, cit., p. 137 (Confesiones evangélicas), p. 144 (Judaísmo), p. 152 (Islam).

142 «Nos encontramos con una colisión entre los derechos del empresario y los del trabajador. Con carácter general, la jurisprudencia resuelve a favor del primero» (M. R. León Benítez, M. M. Leal Adorna, ob. cit., p. 233. 
promiso ante la Divinidad - o bien de determinadas convicciones religiosas concretas que rechazan todo tipo de juramento. Pero el tema no derivó en problema pues encontró pronto una solución, al darse paso a una alternativa entre juramento - ante Dios-y promesa — prestada en nombre del propio honor- ${ }^{143}$. Incluso, en los momentos de la transición política española, operada en el último tercio del siglo XX, se creó un cierto morbo informativo sobre qué autoridades o qué titulares de empleos públicos juraban y quienes prometían en su toma de posesión, como una forma de calificarles y señalarles a priori como creyentes o como laicos, también en orden a suponer qué tipo de actuación política seguiría cada uno o hacia qué sector se inclinaban sus preferencias. La pérdida total de interés en esta materia por parte del público viene a probar que el tema se ha normalizado por completo y en buena parte ha perdido todo su significado ${ }^{144}$, debiendo notarse que entre determinadas Confesiones religiosas existe incluso una negativa al juramento, con base en determinados textos bíblicos ${ }^{145}$.

Una modalidad singular de este modelo de objeción lo ha sido la alegada por determinados cargos públicos tanto a jurar como a prometer, en razón de que no deseaban comprometerse con la legislación española y muy singularmente con la Constitución, a la que rechazaban como Ley Suprema del ordenamiento jurídico. Tal supuesto se ha dado en especial por parte de diputados elegidos para las Cámaras de algunas Comunidades Autónomas, disconformes con la estructura política del Estado, e incluso con la misma adscripción a éste de sus «países» o «naciones», para los que pretendían la independencia o bien formas de integración en España diferentes de las contempladas en la Constitución ${ }^{146}$.

La legislación ha abonado el uso alternativo y libre del juramento o la promesa en las sucesivas disposiciones dictadas — 1977, 1979 — que regulan las fórmulas de toma de posesión o incluso el sistema de libre opción acordado al personal militar — 1980 — y la jurisprudencia del TC ha avalado el deber de jurar o prometer al resolver los recursos nacidos de la negativa a la aceptación política del orden constitucional ${ }^{147}$.

${ }^{143}$ Sobre la alternativa juramento-promesa en nuestro ordenamiento, vid. L. Prieto Sanchis, ob. cit., p. 84 .

${ }^{144}$ Hasta el punto de que la exigencia del juramento se ha visto calificada de «arcaismo» (vid. L. Prieto Sanchis, ob. cit., p. 86) o de «supervivencia de otros momentos culturales y de otros sistemas jurídicos» (TC, en sentencia de 21 de junio de 1990).

${ }^{145}$ Vid. en J. G. Navarro Floria, El derecho a la objeción..., cit., pp. 151-152.

${ }^{146}$ Analizan estos supuestos, que se han dado en varias ocasiones, y que ha motivado diversas decisiones de la jurisprudencia, R. Navarro-Valls, J. Martínez-Torrón, ob. cit., pp. 467-468, que mencionan también alguna bibliografía al respecto.

${ }^{147}$ Vid. G. Escobar Roca, ob. cit., pp. 424 ss. 


\subsubsection{La objeción a formar parte de un jurado}

La existencia del jurado, clásica incluso en otros países, ha encontrado lugar en el ordenamiento español a partir de 1995, cuando se dictó la Ley Orgánica del Tribunal del Jurado - Ley 5/1995, de 22 de mayo — que venía a dar realidad a la norma constitucional que, en el art. $125 \mathrm{CE}$, preveía tal sistema de administración de la justicia ${ }^{148}$.

Formar parte del jurado supone, para el ciudadano llamado a ello, un deber que le viene impuesto no por la propia CE sino por la legislación ordinaria, en concreto por la Ley Orgánica del Poder Judicial de 1985. Un conjunto de incompatibilidades, de exenciones legítimas, y de sanciones para el incumplimiento, envuelven el ejercicio de este deber. No está contemplado de modo específico el derecho a la objeción de conciencia, que queda en manos de la decisión jurisprudencial con apoyo en la posibilidad — que sí se contempla en la ley citada, art. 12.7- de eximir a quienes aleguen en los casos concretos causas que dificulten de forma grave la participación en el jurado ${ }^{149}$.

La negativa a formar parte de un jurado, cuando existe, suele obedecer a motivaciones religiosas; se trata de considerar que un ser humano no puede juzgar a otro - particularmente en materia penal, modalidad en la que suele darse precisamente el juicio mediante jurado- . Tal puede ser, p.e., la situación de quienes interpretan con rigor la norma evangélica «no juzguéis y no series juzgados» (Mt. 7.1) — como hacen los Testigos de Jehová- o la de quienes por su condición personal — los clérigos católicos - tienen prohibido por su propia normativa intervenir en el ejercicio de la jurisdicción civil ${ }^{150}$.

\subsubsection{Los matrimonios entre personas del mismo sexo}

Durante toda la historia, y hasta fechas muy recientes, la aceptación de las uniones homosexuales como matrimonios ha resultado ser un fenómeno del

${ }^{148}$ Vid. al respecto J. M. González del Valle, ob. cit., p. 312; asimismo, J. Martínez-Torrón, «Ley del jurado y objeción de conciencia», en Revista Española de Derecho Constitucional, 48, 1996, p. 119.

${ }^{149}$ La Ley reguladora del Jurado «no contempla como causa específica de abstención la objeción de conciencia, si bien en el elenco de motivos que eximen de la obligación se incluye una referencia genérica a "cualquier otra que ... dificulte de forma grave el desempeño de la función del jurado" (art. 12.7); tal vez a través de esa cláusula pudiera articularse un reconocimiento de la objeción» (L. Prieto Sanchis, ob. cit., p. 84).

${ }^{150}$ No ha dejado de afirmarse que la obligación de formar parte de un jurado no es de por sí severamente coercible, y que se puede "prever un futuro halagüeño para quienes invoquen, entre otras causas que dificultan de forma grave el desempeño de la función de jurado, la propia conciencia» (J. M. González del Valle, ob. cit., p. 314). 
todo desconocido. Su actual admisión en los ordenamientos jurídicos de diferentes países es hoy una realidad del todo nueva. Y de aquí ha nacido un nuevo supuesto de objeción de conciencia, la de los funcionarios públicos llamados por su cargo a intervenir en la celebración de tales matrimonios o uniones matrimoniales no heterosexuales ${ }^{151}$.

Dada la novedad del hecho, aún es pronto para predecir el futuro de este tipo de objeción, sin que tampoco haya habido en España espacio temporal suficiente para sentar al respecto una legislación y una jurisprudencia firmes y consolidadas, tal como sí se ha hecho en algunos países ${ }^{152}$. En el ordenamiento español, lo deseable hubiese sido introducir en la legislación ad hoc una cláusula de conciencia, lo que estuvo a punto de lograrse sin que finalmente prosperase tal iniciativa. En consecuencia, los jueces encargados del Registro Civil, a quienes toca la inscripción de estos matrimonios, y los alcaldes y concejales, a quienes toca la celebración, carecen de un específico apoyo legislativo para eludir su participación en la realización de un tipo de uniones que sus conciencias rechazan.

Amplia parte de la doctrina considera que el derecho a la objeción está fundamentado como una directa derivación de la libertad ideológica y religiosa del art. 16.1 CE. Tratándose de un hecho relativamente nuevo, y por tanto de un modelo de objeción que se está incoando en la práctica y en la normativa, aún pisamos al respecto un terreno en que la doctrina ha tenido escasa ocasión de desarrollarse. En todo caso, resulta claro que los funcionarios públicos llamados por la ley a este tipo de actuaciones se ven en el caso de obrar contra sus convicciones éticas, y rechazan en nombre de su libertad de conciencia la actuación que les correspondería llevar a cabo. Cabe encontrar en la jurisprudencia constitucional una protección a esta libertad siempre que no entrañe un peligro para el sistema jurídico ${ }^{153}$.

Es cierto que, tras la Ley 13/2005 —que admitió este tipo de matrimonios, varios jueces plantearon recursos de inconstitucionalidad que no fueron aceptados. Y asimismo, se cuenta hoy con varias sentencias que niegan el derecho a la objeción de conciencia ante la celebración de matrimonios no heterosexuales. La

${ }^{151}$ R. Navarro-Valls, «La objeción de conciencia a los matrimonios entre personas del mismo sexo», en Revista General de Derecho Canónico y Eclesiástico del Estado, 9, septiembre 2005, pp. 3-22.

152 «Lo que se trata de dilucidar es el derecho (o no) que asiste a la persona para no tener que cumplir una ley si va en contra de su conciencia y se ha de pensar que el matrimonio homosexual (estemos o no de acuerdo con él) puede estarlo. Por ello, hubiese sido hora que el legislador español regulase directamente el tema de la objeción de conciencia, tal y como lo hizo el canadiense o, en un supuesto muy parecido, en el caso de uniones de hecho, el danés» (M. R. León Benítez, M. M. Leal Adorna, ob. cit., p. 234.).

${ }^{153}$ Vid. M. R. León Benítez, M. M. Leal Adorna, ob. cit., que en sus pp. 273-278 ofrecen una especial referencia a la normativa y la jurisprudencia sobre los matrimonios homosexuales; de la objeción de conciencia en este punto se ocupan en especial en las pp. 277-278 
jurisprudencia no ha acertado aún a fijar criterios que puedan resultar convincentes para estas denegaciones de libertades, y el tema se encuentra en una fase en que será necesario esperar a que se consoliden en la doctrina y en la práctica los derechos objeto de discusión.

\subsubsection{La simbología religiosa}

Es éste otro campo novedoso, pues tan sólo en fechas muy próximas al momento presente ha saltado a la opinión pública, a la legislación, y a los tribunales, la temática de la simbología religiosa, muy en particular el velo islámico junto con otros indumentos u ornamentos personales de carácter religioso, así como la presencia de símbolos religiosos en los espacios públicos ${ }^{154}$. Algunos Estados, a título de defensa de su carácter laico ${ }^{155}$, han calificado los usos de algunos símbolos — muy en especial el velo islámico — «como contrarios a la neutralidad y laicidad del Estado», y de ello se han seguido normativas de prohibición, control y rechazo de aquéllos ${ }^{156}$. La doctrina ya lleva un tiempo interesándose por el tema, y fuera de España se cuenta ya con una variada normativa y jurisprudencia en este ámbito, tanto a niveles nacionales como internacionales ${ }^{157}$.

En España, la vestimenta islámica, fuera de algunos incidentes aislados sin mayor relieve ni transcendencia jurídica, no ha creado hasta el presente grandes problemas $^{158}$. Y sí que se han presentado, en cambio, algunas cuestiones más controvertidas, que han comenzado a llegar a los tribunales, sobre la presencia en lugares públicos de símbolos religiosos, en particular del crucifijo.

${ }^{154}$ Subraya la importancia y el significado actual de los símbolos religioso en la esfera pública A. Motilla de la Calle, «Consideraciones generales», en A. Motilla (coord.), El pañuelo islámico en Europa, Marcial Pons, Madrid 2009, p. 10. Vid. asimismo J. J. Guardia, Libertad religiosa y urbanismo, Eunsa, Barañain 2010.

${ }^{155}$ Vid. al respecto S. Cañamares Arribas, Libertad religiosa, simbología y laicidad del Estado, Thomson Aranzadi, Pamplona 2005.

${ }^{156}$ Vid. M. J. Ciáurriz, «Laicidad y Ley sobre los símbolos religiosos en Francia», en A. Motilla (coord.), ob. cit., p. 92; J. Robert, «La läicité et le vêtement», en Anuario de Derecho Eclesiástico del Estado, XXVII, 2011, pp. 433 ss.

${ }^{157}$ Vid. el Epígrafe «Libertad de expresión y símbolos religiosos» en J.A. Souto Paz, Comunidad política, cit., p. 362.

158 «En España, el uso de símbolos religiosos personales en la escuela se ha planteado hasta ahora en menor medida. Los casos más conocidos se refieren a conflictos derivados del uso del velo islámico femenino y se han dado en la Comunidad de Madrid, adquiriendo en su día cierto relieve en la opinión pública, sin pasar nunca del ámbito de las soluciones administrativas» (R. Navarro-Valls, J. Martínez-Torrón, ob. cit., p. 301; en pp. 301-302 exponen en detalle el par de pequeños conflictos que alcanzaron en su día un mayor eco). 
Se trata de un problema que ha alcanzado una importante repercusión internacional como consecuencia del llamado caso Lautsi, originado en Italia a partir de la solicitud de una mujer que pedía que se retirara el crucifijo de la escuela a la que acudía su hijo. Sustanciado el tema ante las autoridades italianas, y ante la respuesta negativa de las mismas a lo solicitado, el caso llegó hasta el Tribunal Europeo de Derechos Humanos, que había de estudiar el problema en dos importantes sentencias sucesivas. En la primera, de 3.XI.2009, el TEDH dio la razón a la solicitante ${ }^{159}$. Sin embargo, apelada la sentencia por el gobierno italiano, el citado Tribunal, en nueva y definitiva sentencia del 11.III.2011, avaló que la presencia del crucifijo en las aulas escolares no viola el derecho a la libertad de conciencia. Esta solución última del caso Lautsi por parte del TEDH —que como marca la doctrina a seguir por Italia, con evidente influencia en el resto del contexto internacional — parece llamada a señalar vías de futuro para esta problemática de la presencia del crucifijo en lugares públicos ${ }^{160}$, y posiblemente no tan sólo del crucifijo, sino de otras diversas formas de simbología religiosa.

Por lo que hace a España, se han dictado entre nosotros todavía muy pocas sentencias al respecto; pueden señalarse como significativas tanto alguna contraria a la presencia del crucifijo en la escuela (Tribunal de $1^{\mathrm{a}}$ instancia de Valladolid, 2008), como otra buscando una vía de común conformidad (Tribunal Supremo de Justicia de Castilla y León, 2009, sobre igual tema), y otra favorable a la presencia del crucifijo en el Salón de Plenos del Ayuntamiento de Zaragoza (Juzgado de la Contencioso Administrativo no 3, 2010) ${ }^{161}$.

Acabamos de emplear la expresión «esta problemática»: las perspectivas sobre la misma en España — como parece evidente- no han llegado aún a concretarse en una doctrina que pueda ofrecer a la vez justicia y seguridad ${ }^{162}$.

\subsection{Especial referencia a la objeción de conciencia en el sector de la educación}

En España, no ha constituido este tema un campo particular de conflicto entre ley y conciencia hasta tiempos muy recientes. Los Acuerdos que el Estado es-

${ }^{159}$ Vid. E. Relaño Pastor, «El asunto del crucifijo en el Tribunal Europeo de Derechos Humanos: hacia una solución de compromiso», en Anuario de Derecho Eclesiástico del Estado, XVII, 2011, pp. 393 ss.

${ }^{160}$ Se ocupan en detalle del tema I. Martín Sánchez, «El caso Lautsi ante el Tribunal Europeo de Derechos Humanos», y L. Martín-Retortillo, «La situación del crucifijo como símbolo religioso en los países de la Unión europea: normativa y jurisprudencia», ambos en prensa en el Anuario de Derecho Eclesiástico del Estado, XXVIII, 2012.

${ }^{161}$ Vid. el Epígrafe «La cuestión del crucifijo en España dentro y fuera del ámbito escolar», en R. Navarro-Valls, J. Martínez-Torrón, ob. cit., pp. 390-393.

${ }^{162}$ Señala la evolución del tema de los símbolos religiosos, hasta fechas recientes, L. MartínRetortillo, «Símbolos religiosos en actividades y espacios públicos», en Id., Estudios sobre Libertad religiosa, Editorial Reus, Madrid 2011, pp. 219 ss. 
pañol firmó, en 1979 con la Santa Sede ${ }^{163}$, y en 1992 con las Confesiones minoritarias $^{164}$, prevén todos ellos la enseñanza en la escuela de la correspondiente religión, y determinan las condiciones en que ha de realizarse la misma ${ }^{165}$. Sin duda que la aplicación de tales normas ha supuesto afrontar diversas dificultades: forma y requisitos de designación así como estabilidad del profesorado ${ }^{166}$, carácter y consideración académica de la asignatura correspondiente en el conjunto de los planes de estudio...; pero en muy pocas ocasiones estos problemas han supuesto desacuerdos o dificultades insalvables y, en todo caso, éstos no se han solido presentar bajo la modalidad de objeciones de conciencia. Tanto más cuanto es constante norma de la legislación al respecto el mantener siempre el respeto a la libertad del alumnado, de modo que la enseñanza religiosa no ha sido nunca obligatoria. Y, en consecuencia, no se habían deslizado hasta ahora en este terreno problemas especialmente graves relacionados de modo directo con la objeción de conciencia.

Las dificultades actuales proceden de la implantación en los planes de estudio de una nueva asignatura obligatoria, denominada «Educación para la ciudadanía ${ }^{167}$ y, en conexión con la misma, de otras enseñanzas de contenido sexual y cuestiones conexas. El conflicto brota de dos fuentes: la obligación constitucional de respetar la libertad de los padres sobre la enseñanza moral dada a sus hijos, y la orientación contraria a tal norma que los poderes públicos han venido a dar a las citadas nuevas materias docentes ${ }^{168}$.

${ }^{163}$ Acuerdo de 3 de enero de de 1979, sobre Enseñanza y Asuntos culturales (vid. en J. Fornés, M. Blanco, B. Castillo, F. Pérez-Madrid, ob. cit., pp. 109-112).

${ }^{164}$ Arts. 10 de los tres Acuerdos de 1992, en J. Fornés, M. Blanco, B. Castillo, F. Pérez-Madrid, ob. cit., p. 136 (Entidades evangélicas), pp. 142-143 (Judaísmo), pp. 150-151 (Islam).

165 Vid. J. M. González del Valle, «La Enseñanza», en J. Ferrer Ortiz (coord.), Derecho Eclesiástico del Estado Español, cit., pp. 273 y ss.; I.C. Ibán, «Enseñanza», en I.C. Ibán, L. Prieto, A. Motilla, Manual de Derecho Eclesiástico, cit., pp. 297 y ss.; P. Lorenzo, Libertad religiosa y enseñanza en la Constitución, Centro de Estudios Políticos y Constitucionales, Madrid 2011, pp. 99 ss.

${ }^{166}$ Vid. R. Rodríguez Chacón, «Los profesores de Religión católica en la Jurisprudencia», en Anuario de Derecho Eclesiástico del Estado, XXI, 2005, pp. 243 ss.

${ }^{167}$ Vid., en el Anuario de Derecho Eclesiástico del Estado: J.M. Martí, «La Educación para la Ciudadanía» (XXIII, 2007, pp. 211 y ss.); A. Castro Jover, «Los valores de la Democracia y Educación para la Ciudadanía» (XXIV, 2008, pp. 291 y ss.); Y. Gómez Sánchez, «Libertad religiosa y derecho a la Educación: un comentario sobre la asignatura Educación para la Ciudadanía y los Derechos Humanos» (XXIV, 2008, pp. 313 y ss.); R. Palomino, «Laicidad y Ciudadanía» (XXIV, 2008, pp. 337 y ss.); M. Areces Piñol, «Derecho a objetar en el ámbito educativo: educación para la ciudadanía. Resoluciones judiciales» (XXV, 2009, pp. 343 y ss.).

${ }^{168}$ M. T. Areces Piñol, ob. cit., pp. 348. 
Según establece el art. 27.3 CE, «los poderes públicos garantizan el derecho que asiste a los padres para que sus hijos reciban la formación religiosa y moral que esté de acuerdo con sus propias convicciones». Una norma obviamente del más alto rango y de obligado cumplimiento, cuya violación por parte de la normativa escolar se acerca al terreno de la inconstitucionalidad, tanto más cuanto que «la formación moral o religiosa es una parte integrante de la libertad de educación, cuya raíz se encuentra en el necesario respeto y protección del derecho de libertad de pensamiento, conciencia y religión ${ }^{169}$.

Nada de eso tendría por qué suceder por el hecho de establecerse una materia de estudio destinada a educar a los alumnos en la ciudadanía. El problema no radica en la asignatura en sí misma, sino en sus programas, contenidos y textos utilizados para su enseñanza, ya que «la $\mathrm{EpC}$ puede servir para explicar cosas diferentes según la interpretación que hagamos de los términos que la definen. Se incidirá o no en la esfera moral del alumno dependiendo de la perspectiva que se adopte para explicarla» ${ }^{170}$. Cuando se ha buscado proporcionar por esta vía a los estudiantes una formación contraria o ajena a la formación religiosa y moral elegida por sus padres ${ }^{171}$, se ha creado un innecesario - pero, o pretendido, o cuando menos previsible - conflicto, que conecta de modo directo con la objeción de conciencia a la que están recurriendo muchas familias para evitar el adoctrinamiento moral de sus hijos en una línea que contrasta con sus personales convicciones.

Es por esta causa por lo que en torno a la "Educación para la Ciudadanía"172 «se ha producido un desencuentro social importante» ${ }^{173}$; y son numerosas las asociaciones de padres y de profesores estiman que la $\mathrm{EpC}$ invade el terreno de aquellas cuestiones morales en la que la Constitución reserva a los padres, en su art. 27.3 , el derecho a decidir sobre la educación de sus hijos ${ }^{174}$.

${ }^{169}$ J.A. Souto Paz, Comunidad política, cit., p. 400.

${ }^{170}$ A. González-Varas, «Cuestiones controvertidas relativas a la enseñanza en España: La Educación para la ciudadanía», en I. Martín Sánchez, M. González Sánchez, Algunas cuestiones controvertidas del ejercicio del derecho..., cit., p. 212.

171 «La idea que subyace a la Educación para la ciudadanía es la del republicanismo, es decir, de la laicidad francesa en su acepción de ideología de la secularidad» (J. M. Martí, ob. cit., p. 229).

${ }^{172}$ Vid. sobre la normativa y su interpretación en este campo R. León Benítez, M. M. Leal Adorna, ob. cit., pp. 237-248.

${ }^{173}$ R. Palomino, «Laicidad y ciudadanía», cit., p. 355.

${ }^{174}$ Vid. J. M. González del Valle, ob. cit., pp. 331; J. L. Martínez López-Muñiz, «La Educación en la Constitución española», en Persona y Derecho, 6, 1979, p. 249; J. Ferrer Ortiz, «Responsabilidad ética de la educación», en VV.AA., Libertad, igualdad y pluralismo en la educación. Encuentros sobre educación escolar en el Escorial, Universidad Complutense, Madrid 2003, pp. 158 ss. 
La controvertida materia ${ }^{175}$ aparece en la Ley Orgánica 2/2006, de 3 de mayo, sobre Educación ${ }^{176}$; la inquietud frente a la misma nació pronto por los motivos arriba indicados ${ }^{177}$. La Conferencia Episcopal, en Declaración del 28 de febrero de 1987, la consideró inaceptable tal como había sido planteada, y no tardaron en aparecer numerosos objetores de conciencia — más de 50.000 — que la rechazaban para sus hijos ${ }^{178}$, mientras el Ministerio de Educación se mantenía firme en declinar toda acusación acerca del sentido adoctrinador de la materia, por encima de la evidente intromisión de ésta en terrenos afectivos, de relaciones personales, de construcción de la conciencia, e incluso en temas que tocan a la sexualidad humana, los modelos de familia, la salud reproductiva, las orientaciones sexuales $^{179}$, terrenos todos en los que la enseñanza de Educación para la Ciudadanía tiende a justificar las muchas reformas introducidas por la más reciente legislación en estos campos ${ }^{180}$, inspirada en unos principios contrarios a la visión ética propia de las Confesiones religiosas y, muy en especial, de la Iglesia católi$\mathrm{ca}^{181}$. Y en esta línea se ha desarrollado en buena parte el tratamiento normativo del tema por parte de la legislación autonómica y de las propuestas editoriales ${ }^{182}$.

El problema, a través de los movimientos objetores mencionados, ha llegado ya hasta los tribunales, cuya jurisprudencia es hoy por hoy todavía insegura y contradictoria. Son ya unos trescientos los fallos judiciales favorables a los padres que han presentado su objeción, siéndoles contrarios unos treinta. Cuando los recursos han llegado hasta el TS, cuatro sentencias sucesivas de éste en 2009 rechazaron la objeción sobre la base — que ya conocemos, pues fue similar en su día la sentencia de 1987 del TC sobre el aborto- de que no existe un derecho a la objeción si el mismo no está expresamente declarado en la ley, no considerando aplicable la tesis de que estas objeciones están contenidas en el derecho de libertad ideológica y religiosa del art. 16.1 CE. Pero, aun así, el TS no esculpa por

175 «La puesta en marcha de la asignatura "Educación para la ciudadanía" ha ocasionado una auténtica polvareda político-social en nuestro país» (M. Moreno Antón, «La Educación para la Ciudadanía en clave jurídica», en Anuario de Derecho Eclesiástico del Estado, XXIV, 2008, p. 411).

${ }^{176}$ Vid. sobre la promulgación de la misma M. del M. Moreno Mozos, «Educación para la ciudadanía: ¿Enseñanza de la Constitución y los Derechos Humanos?», en Anuario de Derecho Eclesiástico del Estado, XXIV, 2008, p. 427; en pp. 431 ss. la autora expone el iter de elaboración de esta Ley.

177 Vid. M. M. Serrano Pérez, «La Educación en valores y la libertad de conciencia en los límites constitucionales», en Anuario de Derecho Eclesiástico del Estado, XXVII, 2011, pp. 380-389.

${ }^{178}$ Sobre las bases de la objeción, vid. R. Palomino, ob. cit., pp.357-358.

${ }^{179}$ Vid. sobre la inserción y contenido de estos temas en la Ley, M. del M. Moreno Mozos, ob. cit., pp. 435 ss.

${ }^{180}$ Vid. M. Moreno Antón, ob, cit., p. 417.

${ }^{181}$ Vid. M. T. Areces Piñol, ob. cit., p. 359.

${ }^{182}$ Vid. M. Moreno Antón, ob. cit., pp. 417-418. 
completo de toda sospecha a la EpC, en cuanto su incidencia queda dependiente de los libros de texto y de la orientación que se dé a la enseñanza. El tema está abierto, tanto más que diversas familias que han visto rechazada su objeción por el TS han elevado recursos al TC, e incluso está solicitada en algún caso la intervención del Tribunal Europeo de Derechos Humanos ${ }^{183}$.

Por otro lado, debe mencionarse aquí otra cuestión muy distinta, pero que toca igualmente a las opciones de conciencia en el campo educativo. Se trata de un precepto, contenido en los artículos 12 de los Acuerdos de 1992 con tres Confesiones religiosas, de los que ya se ha hecho mención en relación con las festividades laborales. En su párrafo final, tales artículos se refieren a los estudiantes y examinandos pertenecientes a las Confesiones indicadas. Para los evangélicos, algunas de cuyas iglesias celebran el sábado, se dispone que los alumnos miembros de las mismas «que cursen estudios en centros de enseñanza públicos y privados concertados, estarán dispensados de la asistencia a clase y de la celebración de exámenes desde la puesta del sol del viernes hasta la puesta del sol de sábado, a petición propia o de quienes ejerzan la patria potestad o tutela». Para los judíos, una igual dispensa les protege a los mismos efectos y bajo las mismas condiciones tanto durante el sábado como en sus días festivos anuales, y otro tanto se dispone para los musulmanes. Y, por lo que hace a exámenes, oposiciones y pruebas selectivas, convocadas para el ingreso en las Administraciones públicas, cuando hayan de celebrase en los citados días de descanso de cualquiera de las tres Confesiones interesadas, pasarán para los miembros de éstas a una fecha alternativa, «cuando no haya causa motivada que lo impida» ${ }^{184}$. Una forma al menos favorable para prevenir conflictos y evitar objeciones, al abrir la posibilidad del respeto a las diferentes creencias religiosas en un tema relacionado con la enseñanza.

${ }^{183}$ Vid. esta información, cuidadosamente detallada, en R. Navarro-Valls, J. Martínez-Torrón, ob. cit., pp. 281 ss.

${ }^{184}$ Vid. los textos citados de los Acuerdos en J. Fornés, M. Blanco, B. Castillo, F. Pérez-Madrid, Legislación eclesiástica, cit., respectivamente pp. 137, 144 y 152. 
Title:

LEGAL DUTIES AND MORAL CONVICTIONS IN SPANISH LAW

\title{
Resumen
}

\begin{abstract}
Human rights literature has long been dealing with the issue of conscientious objection, which has recently been described, very adequately, as «a conflict between conscience and law». Based on this premise, this article brings this topic to a higher, more general level and refers to the moral convictions - of ethical or religious naturethat any individual may hold, and to the conduct that may follow such convictions in view of the legal duties imposed by the law on citizens. This is no doubt a universal problem: the consistence of human behavior as the product of personal ethics, and the related issue of how States are to respond when personal conscience and the existing legal order are incompatible. The author, as suggested in the title, deals with these matters in the context of Spanish Law, approaching conscientious objection as a multi-faceted issue. Special attention is paid to the actual/possible/ideal solution of a number of factual situations with a view to arriving at an outcome where no one is constrained to disregard his legal duties to the detriment of his freedom and personal rights. This work contemplates conscientious objection from a very up-to-date perspective, studying the relevant legal rules on the issue, which is presented as an ethical-legal conflict. In this type of situation, it is not legitimate to disregard the needs of any of the conflicting parties, as in a human rights framework all of them should be involved in fulfilling the twofold duty of abiding by the law and respecting one's own conscience.
\end{abstract}

\section{Palabras clave:}

Objeción de conciencia, Deberes jurídicos, Convicciones morales, Sistemas de objeción de conciencia, Derecho español sobre objeción de conciencia, Derechos Humanos, Libertades Fundamentales.

Key words:

Conscientious Objection, Legal Duties, Moral Convictions, Conscientious Objection Systems, Spanish Law on Conscientious Objection, Human Rights, Fundamental Freedoms 